\title{
Contributions of heat pumps to Demand Response: a case study of a plus-energy dwelling
}

\author{
Laura Romero Rodríguez ${ }^{\mathrm{a}}$, José Sánchez Ramos ${ }^{\mathrm{a}}$, Servando Álvarez Domínguez ${ }^{\mathrm{a}}$,Ursula Eicker \\ ${ }^{a}$ Grupo de Termotecnia. Escuela Técnica Superior de Ingenieros, Seville, Spain. \\ ${ }^{b}$ Research Center for Sustainable Energy Technologies, Stuttgart University of Applied Sciences. 70174 Stuttgart, Germany.
}

\begin{abstract}
Demand Response programs are increasingly used in the electricity sector, since they allow consumers to play a significant role for balancing supply and demand by reducing or shifting their electricity consumption. For that purpose, incentives such as time-based rates have been proposed. The present study analyzes the potential benefits of operating the heat pump of a plus-energy dwelling which participates in a dynamic pricing market, benefitting from the thermal storage capacity of the building. The software TRNSYS 17 has been used to model the building and the supply system. A validation of the model was carried out by using available measurements of the dwelling.
\end{abstract}

Three setpoint temperature scenarios have been considered for sixteen different strategies which depend on temperature and electricity price thresholds, with the aim of determining which alternatives could lead to significant savings while maintaining an acceptable thermal comfort. Several factors such as cost savings, heat pump consumption, ratio of self-consumption of the dwelling and use of the heat pump during peak hours were also evaluated in every case.

The results show that dynamic price thresholds should be used instead of fixed price thresholds, which may cause low activations of the heat pump or overheat the building above the comfort limits. Cost savings up to $25 \%$ may be achieved by using optimal strategies, increasing the self-consumption ratio, having almost no influence on the thermal comfort and achieving significant peak reductions on the grid. The outcomes of this study show the importance of looking at the implications of such strategies on several criteria within a demand response framework.

Keywords: demand response; demand side management; dynamic pricing; setpoint temperature; plus-energy dwellings.

\section{Introduction: the need for Demand Response}

Unlike other energy resources, electricity has to be used when it is generated, since its storage on a large scale is still an intricate task. Utility companies increasingly have to deal with peak demands in constrained networks, so regulating the electricity use is critical. The grid frequency is the indicator of the balance between supply and demand, dropping when the consumption exceeds the supply and increasing when generation exceeds consumption. In addition, with the increasing penetration of intermittent renewable generation there is a growing need for ancillary services to absorb the related disruptions [1].

Blackouts happen if the supply is incapable of meeting the demand, which can be solved either by investing in new power plants and transmission lines, or by reducing the electricity demand. However, the first option might not be economically feasible, since critical periods only occur a few hours per year and increasing the price of electricity would not easily solve the problem. For this reason, in order to relieve the electricity grids it is of paramount importance to be able to reduce the peak demands or shift the loads during peak periods through Demand Side Management (DSM) and control systems. As a by-product there may exist significant economic gains if the adequate strategies are followed. 
A practical example to illustrate this situation is shown for Ontario, Canada [2]. Here the highest $3 \%$ of peak load occurs for less than 15 hours during a year, but costing more than 130 million US dollar per year to maintain the peak generation capacity. For this reason, a program called "peak saver" was created, which allows utilities to remotely control thermostat settings at volunteering homes, therefore reducing the air conditioning peak loads by setting the thermostats a few degrees higher on hot summer days in which the peaks occur.

Thanks to the technological advances in control and communication systems, Demand Response (DR) is emerging as an interesting strategy for peak demand reduction, allowing direct load control, timeof-use tariffs and interruptible programs. Many different approaches are being evaluated to participate in these markets, for example by determining the potential of electric vehicles to provide reserve power as a vehicle-to-grid concept [3]. Nonetheless, incentives, dispatch methods and compensation of DR remain challenges that restrain system planners and operators from adopting these strategies [4]. During the past years there has been a noticeable increase of interest in DR strategies, which is reflected in the rise of scientific publications from 219 in the year 2000 up to 1418 publications in 2016 (as shown in Science Direct).

As it is widely known, buildings are responsible for a large portion of the total electricity consumption in many countries, and they are critical in efforts towards attaining the much needed operational flexibility in the grid [5]. Among the different contributors, heating, ventilation and air conditioning (HVAC) systems are the most influential. To reduce HVAC energy consumption, a very simple and effective way would be to improve the control strategies, allowing the use of DR instead of replacing the existing equipment.

Currently, the concept of DR is mainly applied in relation to the electricity grid, but similar benefits can also be obtained from district heating systems [6], especially if heat pumps (HP) or co-generation engines are available to connect the electrical and thermal energy sectors (sector coupling). District heating systems are able to de-couple the fluctuations in the heating demands of buildings from the grid, therefore smoothing the peaks. When heat pumps are used for domestic hot water and heating systems supply, it is advantageous to use low temperature distribution networks as the heat source compared to ambient air. Low temperature heat can be provided by waste heat, low depth geothermal energy, Photovoltaic Thermal (PVT) collectors or comparable sources. In a cold district heating network $(\mathrm{CDHN})$, the supply temperature is less than the one required for heating or Domestic Hot Water (DHW). Low network temperatures reduce heat losses in the distribution system, improve the efficiency of the HVAC equipment and allow the use of other renewable energies.

If the electricity market conditions are favorable, heat can be produced with the HVAC system to preheat, heat or even overheat the building, and thus storing energy in the building thermal mass or in storage tanks. This of course depends on the availability of pricing programs which allow time-ofuse (TOU) tariffs. In these tariffs, the prices are set in advance and vary throughout the day, being higher in peak periods and lower in off-peak periods. Conversely, in Dynamic or Real-Time Pricing (RTP) customers are notified of the rates on a day-ahead or hour-ahead basis. A dynamic electricity market is already available in many countries for large consumers, and it is being extended to residential customers, which increasingly generate their own renewable energy and become prosumers. By using photovoltaics with or without battery storage, buildings may achieve high self-sufficiency levels and reduce network distribution losses and fossil fuel use in the electricity sector.

According to [7] the status of EU Member States regulation concerning DR can be divided into three groups: those who have yet to seriously engage with DR reforms (Portugal, Spain, Italy, Croatia, the Czech Republic, Bulgaria, Slovakia, Hungary, the Baltics, Cyprus and Malta), those in the process of enabling DR through the retailer only (Germany, the Nordic countries, the Netherlands and Austria) 
and those who enable both DR and independent aggregation (Belgium, France, Ireland and the UK). A very complete review of dynamic pricing programs in the U.S. and Europe has been done [8], stating that Europe has a strong focus on large-scale roll-outs of smart meter devices.

\subsection{Thermal mass storage and setpoint strategies}

Buildings have a thermal mass that provides inertia, taking some time to heat up or cool down. Like other technologies to store energy, this inherent property can be used to store energy at peak periods and preheat or precool the building, but is available at no additional investment cost. Given the right control system, an electric heater or electric Heat Pump could be used flexibly depending on the grid conditions, without significantly compromising the thermal comfort of the occupants and contributing to the reduction of peak loads. Using the thermal inertia enables electricity and thermal demand to be partially decoupled through flexible HVAC operation while maintaining thermal comfort. During hours of no occupancy this strategy has an even higher impact, since it allows to relax the comfort constraints.

One way to increase the potential of using the structural thermal mass of a building for DR purposes could be to use higher temperature setpoints during off-peak periods, preheating or even overheating the building and lowering the setpoints during peak periods. A promising technology to activate the thermal storage mass in buildings are the Thermally Activated Building Systems (TABS), which include pipes or ducts embedded in the building surfaces to work as heat exchangers, providing heat or cooling and storing heat in the thermal mass [9]. TABS help to activate the thermal mass of the building, allowing load shifting strategies. By making use of dynamic pricing strategies there might be significant cost savings, but overheating the building above its normal setpoint temperature results in energy losses, therefore increasing the energy consumption. In addition, raising or lowering setpoint temperatures may have notable peak load reduction potentials, but the operation of the HVAC should also take into account its effect on indoor comfort, which describes the satisfaction of the occupants with the thermal environment and has great influence on their productivity.

In addition, thermal energy storage (TES), which requires an additional water loop to charge and discharge the water tanks, can also be used for DR. According to [10] DR using TES can be categorized into two groups: based on simple heuristic rules and optimal DR control. The major difference is whether these methods consider the trade-off between peak demand reduction and the possible energy increases by load shifting, crucial for achieving electricity cost savings. Oversizing the storage tanks used as thermal energy buffer may also increase the amount of energy which can be shifted, thus improving the flexibility of the system. However, due to higher thermal losses the costs would most likely increase, so the economics should be evaluated in every case.

Among the different technologies available to carry out DR strategies, heat pumps may play a vital role. According to [11], there are three main categories of applications using heat pumps in a smart grid context: stable and economic operation of grids, integration of Renewable Energy Systems (RES) and operation under variable electricity prices. Changing residential space heating from the use of gas boilers towards heat pumps is recognized as a method to reduce emissions and increase the energy efficiency [12]. Heat pumps might become effective in balancing the electricity supply and demand when combined with the thermal inertia of buildings, contributing as well to the integration of renewable energies. They might therefore be able to use dynamic pricing as a means to induce users to generate or absorb electricity depending on the grid imbalance. 


\subsection{Reported cost savings}

The study in [13] presents an algorithm to assign temperature setpoints to price ranges based on discomfort tolerance indexes, with a controller based on Model Predictive Control (MPC) for HVAC usage. They showed that their strategy could lead to significant cost savings. Conversely, [14] developed an advanced controller by combining the use of TRNSYS and Matlab programs. They proposed to reduce the cooling setpoint temperature for precooling before the peak hours start, storing cooling energy in the building and keeping the HVAC system off during the peak hours to reduce energy costs. Another possibility is the one given by [15], in which a controller changes the setpoint temperatures when retail prices are higher than customers preset price, providing up to $10.8 \%$ of energy cost savings.

On the other hand, [16] includes ground-source heat pumps connected to a floor heating system in a smart grid pilot, achieving cost savings of $8 \%$ but increasing the heating demand by $1.4 \%$. Moreover, [17] demonstrated that ground source heat pumps present a high potential as flexible loads when combined with the thermal storage capacity of the building, proposing a load shifting strategy by preheating the building and avoiding peak periods, leading to a reduction of electricity costs of up to $34 \%$. Another strategy was to apply longer preheating times to guarantee that the temperature is stabilized in the first peak period, turning it off during the duration of the peak and thus avoiding higher costs. This study also tested different preheating times, taking into account the outdoor temperature and achieving cost savings of 16-19\%. The work presented in [18] also analyses the potential of a heat pump system, but in this case coupled with solar thermal energy on multifamily buildings. They concluded that the related investment may not be worthwhile, given the rather small associated electricity savings.

Focusing on a combination of air conditioning use and time-shiftable appliances, [19] developed a MPC scheme minimizing peaks and flattening the overall energy use profile by altering the thermostat setpoints in individual homes, removing $10 \%$ of the heating load without affecting the quality of service. Escrivá-Escrivá et al. [20] devised an Energy Management and Control System (EMCS) to schedule electricity end-uses in a University campus, analyzing the effect of different schedules and using different control strategies for HVAC split systems. The results showed a high potential for peak reductions and economic benefits. Korkas et al. [21] presented a novel control algorithm for joint thermal comfort optimization and DSM in microgrids with RES and TES. Conversely, [22] focused on quantifying the potential energy savings in HVAC systems through setpoint and deadband changes. This study also considered the effects of some influential factors on building HVAC energy consumption using building energy simulations. In summary, the study stated that increasing the deadband would result in an increase of energy savings. Alimohammadisagvand et al. [23] investigated DR actions on thermal comfort and energy costs in detached residential houses in a cold climate, reporting maximum annual savings in total energy costs of up to $10 \%$.

There is another issue that should be borne in mind, which is the fact that fewer studies have been performed on the optimal DR control to maximize cost savings by considering also the trade-off between peak demand reduction and the possible energy increase, which is highly nonlinear and complex [10]. Conversely, [24] stated that the increased demand is negligible compared to the large cost savings arising from the system-wide benefits. Apart from that, [25] used a control strategy with a cooling storage system and stated that although the costs were reduced by $24 \%$, the energy consumption increased $20 \%$ due to longer operation of the chiller and pumps compared to the base case. 
In [12], a residential DR context is described, using a multi-objective strategy for space heating and DHW production using heat pumps and a TES system. Chassin et al. [4] presented detailed simulation and performance studies showing how thermostatically controlled electrical loads can provide very valuable energy storage and how they could be prime candidates for fast DR. Also, [26] investigated how residential heat pumps which participate in load shifting can contribute to the reduction of emissions and operational costs. Last of all, [27] analyzed the performance of a dynamic thermostat controller of HVAC systems in homes that have dynamic price of electricity. The consumers in this case set a threshold price that the thermostat uses to set the temperature during peak power price periods. The results show that $12 \%$ of annual energy cost savings for HVAC operation can be achieved without significantly changing the thermal comfort.

\subsection{Aim of the study}

The main purpose of the present study is to analyse the impact of different dynamic pricing strategies on several aspects: cost savings, indoor comfort, heat pump consumption, reduction of the HP use during peak hours and photovoltaic energy self-consumption ratio of the building. The proposed controller can automatically manage the activation of the HP in response to price changes, so that cost savings can be achieved and the overload on the grid during peak periods is diminished by shifting the loads from peak to off-peak periods. However, in order to do so the energy has to be stored in the building, which is possible thanks to the building mass within the thermal envelope, offering a passive thermal storage to shift the electricity demand.

A plus-energy dwelling located in Wüstenrot, Germany has been used as a case study. The TRNSYS [28] software was used to model the building and the supply system. Moreover, a validation of the model has been carried out by using measurements of the real system. One peculiarity of the household is that the HP is connected directly to the building, not to a storage tank which would be the most typical configuration. Although a study focusing on the use of the storage tanks would also be interesting, it is not the aim of the present work. In this way, this study focuses on the thermal storage capacity and flexibility of the building itself. As far as the authors know, no study has been previously done on the potential of dynamic pricing strategies in plus-energy buildings.

The aim is also to analyse the influence of changing setpoint temperature bands (range around the setpoint where room temperature oscillates) with regards to the previously mentioned aspects. Sixteen different strategies have been simulated for three different setpoint temperature scenarios: $20 \pm 0^{\circ} \mathrm{C}$ (in which the system tries to maintain an indoor temperature of $20^{\circ} \mathrm{C}$ all the time), $20 \pm 1{ }^{\circ} \mathrm{C}$ (indoor temperature varying from $19^{\circ} \mathrm{C}$ to $21^{\circ} \mathrm{C}$ ), and $20 \pm 2{ }^{\circ} \mathrm{C}$ (from $18^{\circ} \mathrm{C}$ to $22^{\circ} \mathrm{C}$ ). The analysis is done by using data of the tariffs within a day-ahead market, taking advantage of the flexibility of heat pumps which can be used depending on the grid conditions. Different price thresholds are used, fixed or variable, which either constrain the use of the heat pump during its normal operation or enforce its activation. Temperature thresholds will also be considered to avoid overheating. Another interesting question is whether there may be a good compromise between cost savings, the increased energy consumption, the thermal comfort of the occupants and the contribution to the reduction of the grid's peak load. Several conclusions are drawn and the optimal strategies for each setpoint temperature scenario are presented. 


\section{Case study: Modelling and Simulation}

\subsection{Description of the case study}

The case study is a real dwelling currently being intensively monitored, located in a new district in Wüstenrot (Germany). This district consists of more than 20 plus-energy houses recently built with high insulation standard (KfW 55), each of which have photovoltaic (PV) arrays of different sizes as well as an electrical storage of $5 \mathrm{kWh}$. Heating is provided inside the dwellings by using underfloor heating, supplied by heat pumps which are connected to a cold district heating network located in the area. In addition, each building has thermal energy storage capacity through a space heating tank and a DHW storage tank. Although the case study is still quite special due to its high insulation standard, high PV production, use of underfloor heating and connection to a cold district heating network, it was chosen due to its representativeness of highly energy-efficient future dwellings. It should also be mentioned that measurements of global radiation and outdoor temperature in the location of the dwelling are available.

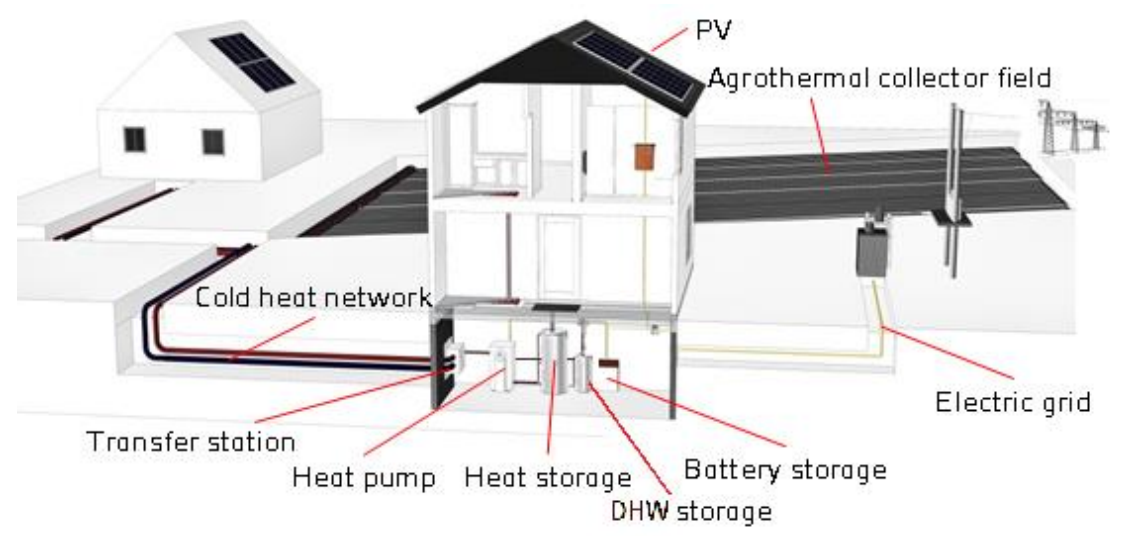

Figure 1: Schematic representation of the building under consideration.

As previously mentioned, one of these monitored dwellings will be used for the present study. The real case under consideration has one particularity: the heat pump is connected directly to the underfloor heating of the building, and the heating tank is located on the return flow. This somehow uncommon configuration has however an advantage: the focus will be on the thermal storage capacity of the building, not on the thermal tank. The different parts of the energy supply system are listed below:

-Photovoltaic collectors: 48 modules $\left(58,4 \mathrm{~m}^{2}\right)$ with a south orientation, and 40 modules $\left(49,5 \mathrm{~m}^{2}\right)$ with a north orientation. Both have a low tilt angle of $15^{\circ}$ (that of the roof). The installation has $13,64 \mathrm{kWp}$ in total.

-Heat pump: ground-source heat pump, connected to the cold district heating network. Used to produce hot water with a thermal capacity of $23.1 \mathrm{~kW}$ and a rated power of $3.7 \mathrm{~kW}$.

-Water heat storage for space heating/cooling: 1000 liters.

-Water heat storage for DHW: 400 liters.

-Electricity storage: $5 \mathrm{kWh}$, used for the optimization of PV self-consumption.

-Sensors and meters: some temperature sensors and heat meters are already installed in the supply system of the dwelling, as well as electricity consumption smart meters for the PV production and heat pump consumption. 


\subsection{Description of the model}

Both the supply system and the building have been modeled in the TRNSYS 17 [28] environment, which allows to perform the planned simulations optimally, in view of the fact that all parameters can be adjusted in a flexible way. The aim was to develop a model which could reflect the reality, so as to be able to validate it with experimental data and analyze the impact of the chosen dynamic pricing strategies.

\subsubsection{Dynamic Building Model}

In order to produce a detailed building model, the building geometry was created with the software SketchUp, which has a plugin for TRNSYS to easily input the geometric information and create a multizone building model (see Figure 2). The thermal zones of the building have been simplified as one per floor, which have horizontal surfaces of $123 \mathrm{~m}^{2}$ and $129 \mathrm{~m}^{2}$. The model reflects the real orientation of the building, as well as the construction materials and windows positions.

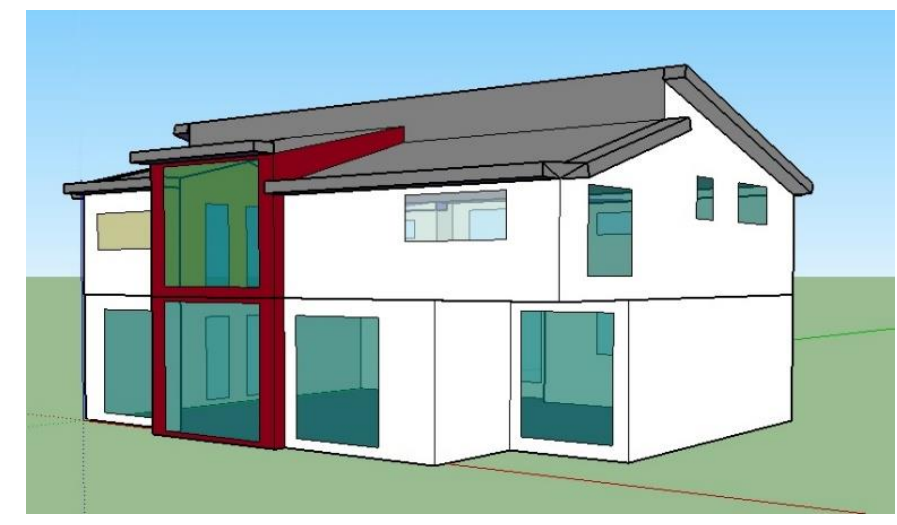

Figure 2: SketchUp model of the building.

Once the SketchUp model was created and integrated within TRNSYS, the next step was to approximate the real conditions of ventilation and internal gains with TRNBUILD. Last of all, so as to model the radiant floor heating an active layer was added to the horizontal surface between both zones. This active layer allows to use the temperature and flow going into its pipes as an input from the heat pump into the multi-zone building model.

\subsection{TRNSYS implementation}

The sizing of all the elements (thermal storage, battery, PV modules, fluid flowrates, etc.) corresponds to the reality. Experimental data has been used for the temperature of the cold district heating network. In addition, data of the manufacturer of the heat pump has been used to modify the curves of the file read by the heat pump type. The chosen timestep for the simulations is 30 minutes, considered as a good compromise between simulation time and accuracy for the purpose of the current study. Typical consumption profiles of a German household have been used for the appliance electricity and DHW. Figure 3 gives an example of the electricity consumption profile during a typical day in February. 


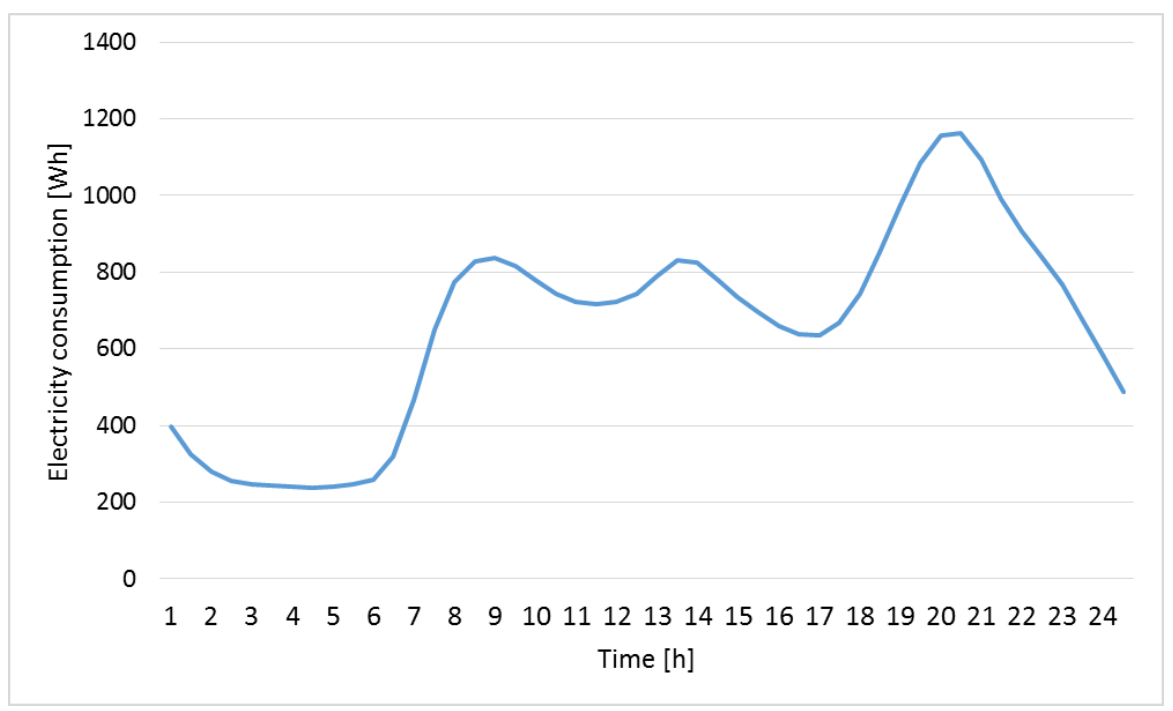

Figure 3: Hourly household electricity consumption during a typical day in February 2017.

Finally, the standard Typical Meteorological Year (.tm2) weather file provided by TRNSYS for the area has been used, updating it by using the available measurements at the location of the dwelling. A representation of the TRNSYS supply model and its connection to the building can be seen in Figure 4 .

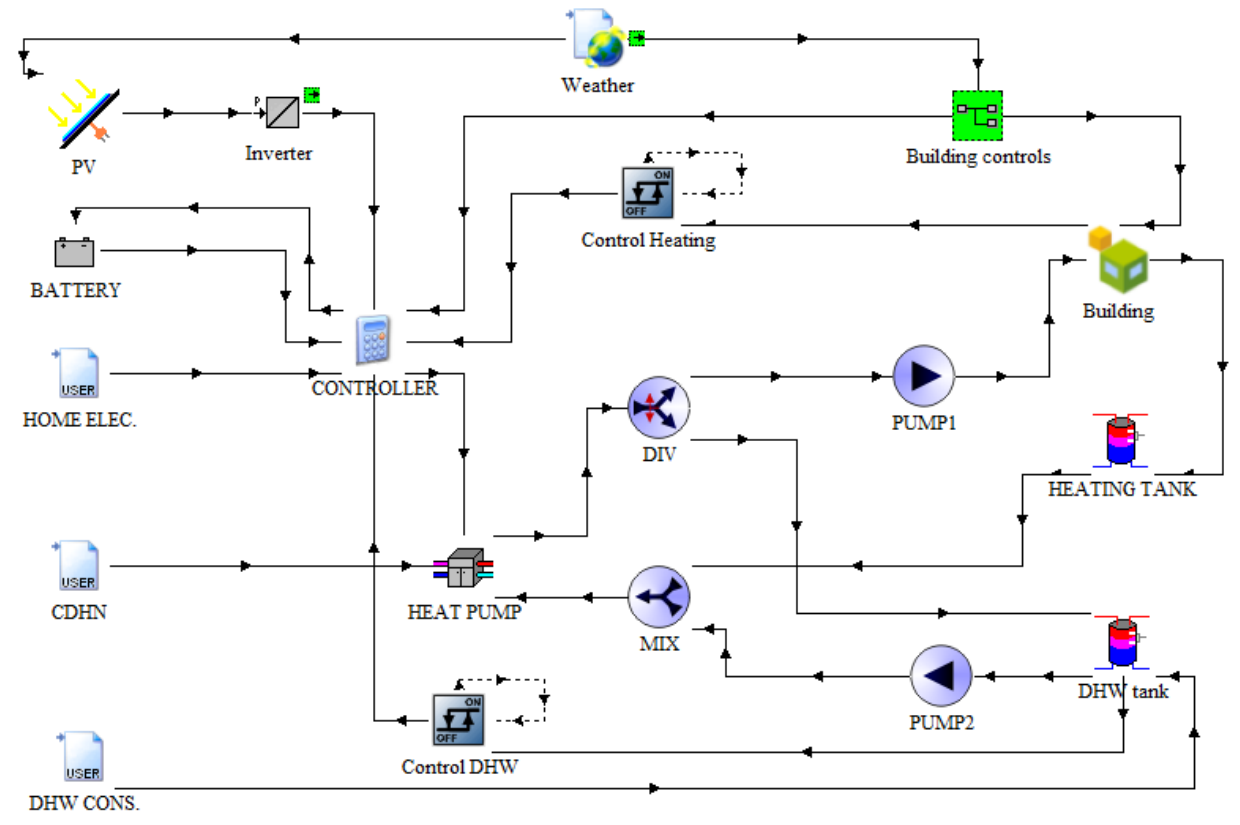

Figure 4: Representation of the TRNSYS model.

The controller of the heat pump was developed after consulting with the inhabitants of the household the way in which the heat pump works in the reality, which gives a priority to the availability of DHW. Figure 5 shows the flowchart of the controls within the simulation. $T_{\text {low }}$ is the lowest temperature of the band in the considered strategy. 


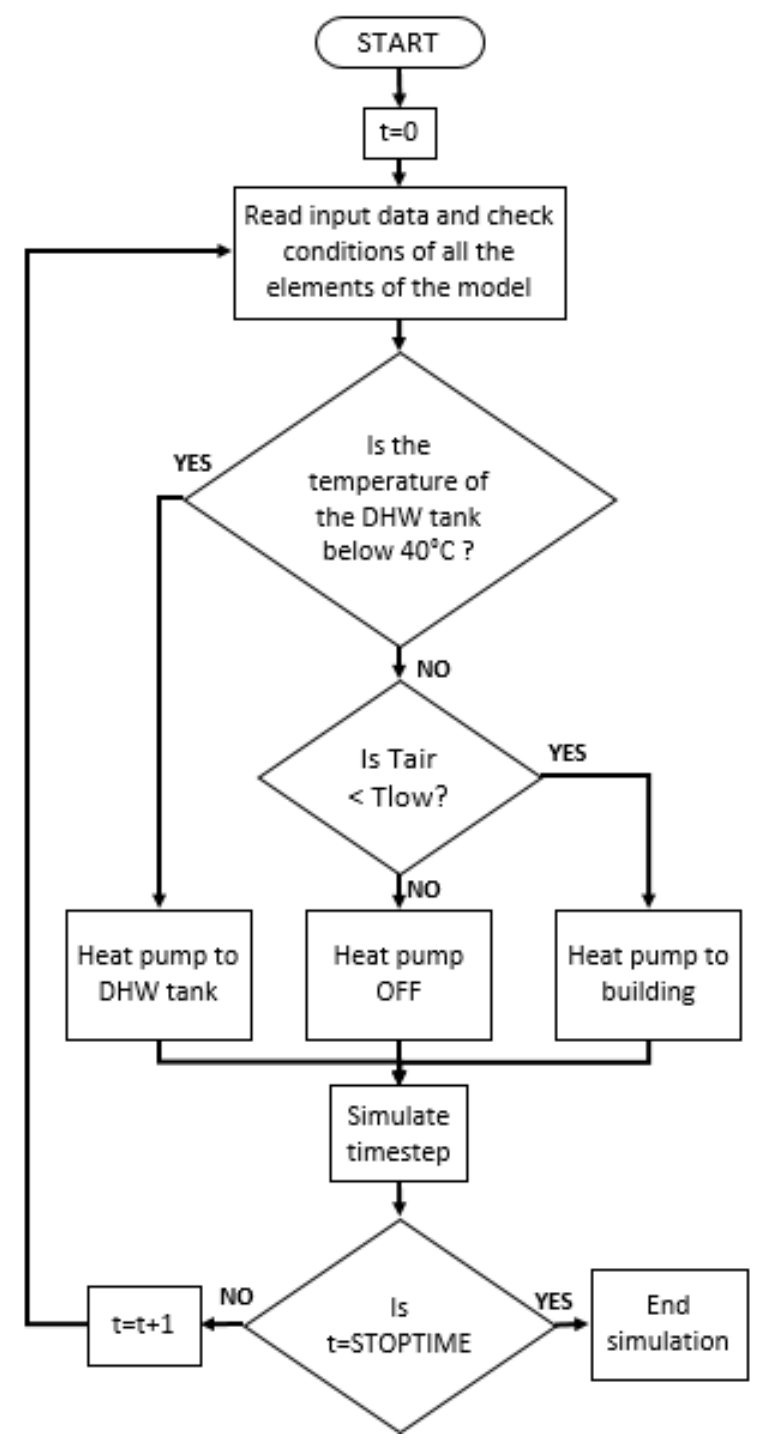

Figure 5: Flowchart of the simulation.

\subsection{Experimental Validation}

Before proceeding to analyze different strategies of dynamic pricing, a validation of the model was considered appropriate so as to check that the behavior of the model was close to the reality. Once the model has been adjusted and validated, the results of the strategies that will be studied can be considered as more reliable and realistic. Due to the difficulties to obtain real data in all the required variables with no perturbations or alterations (due to intervals of no occupancy for example), the period chosen for the validation is limited to the first three weeks of February 2017.

The outcomes of the validation of the model are shown in Figure 6 and Figure 7. Due to the uncertainty regarding the real electricity and DHW consumption only aggregated values have been used for the validation. Using real measurements for some inputs such as the cold district heating network (CDHN) temperature and the same control mode as in the reality, the simulated average daily indoor temperature and the electrical energy for the heat pump are very similar to the measurements. 


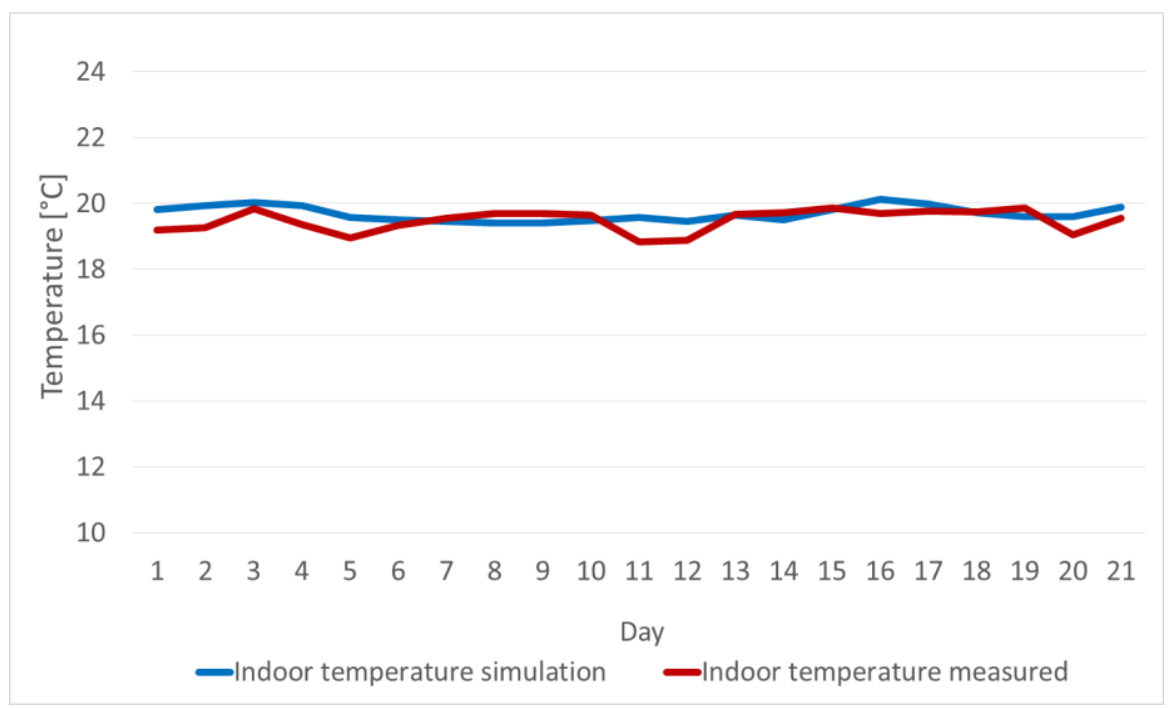

Figure 6: Daily average indoor temperatures, 1-21 February of 2017.

In the case of the PV production, a difference of $4.94 \%$ has been obtained. The heat pump electrical energy consumption has only a $0.20 \%$ difference compared to the monitored value.

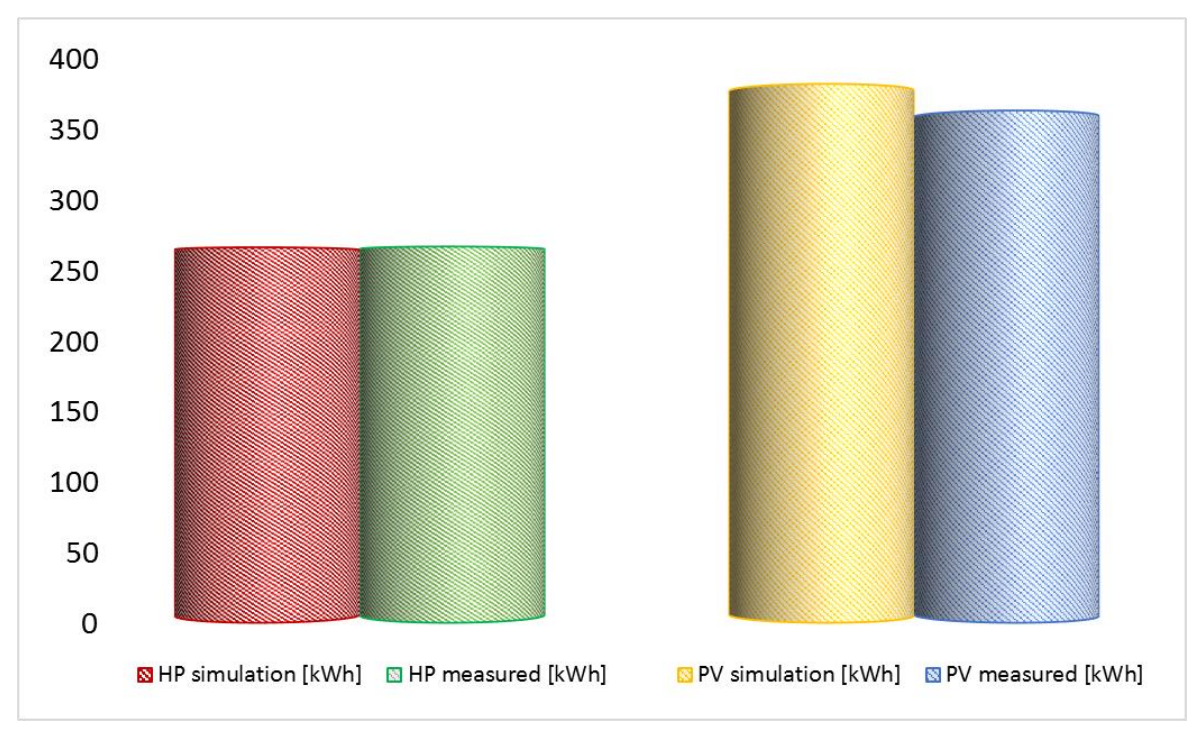

Figure 7: Validation of the model, 1-21 February of 2017.

\subsection{Dynamic pricing strategies}

In this section, different dynamic pricing strategies will be explained in detail. These strategies will be then compared with the situation in which there is no price restriction to use the energy, considered as the base case (strategy 1 ) with a constant electricity price. The focus of the study will be in the month of February, which is the period of the validation of the model. Real prices of the day-ahead German electricity market will be used, with a total of $174.24 € / M W h$ network and feed-in charges and taxes added. The hourly electricity price profile used for the study can be seen in Figure 8. 


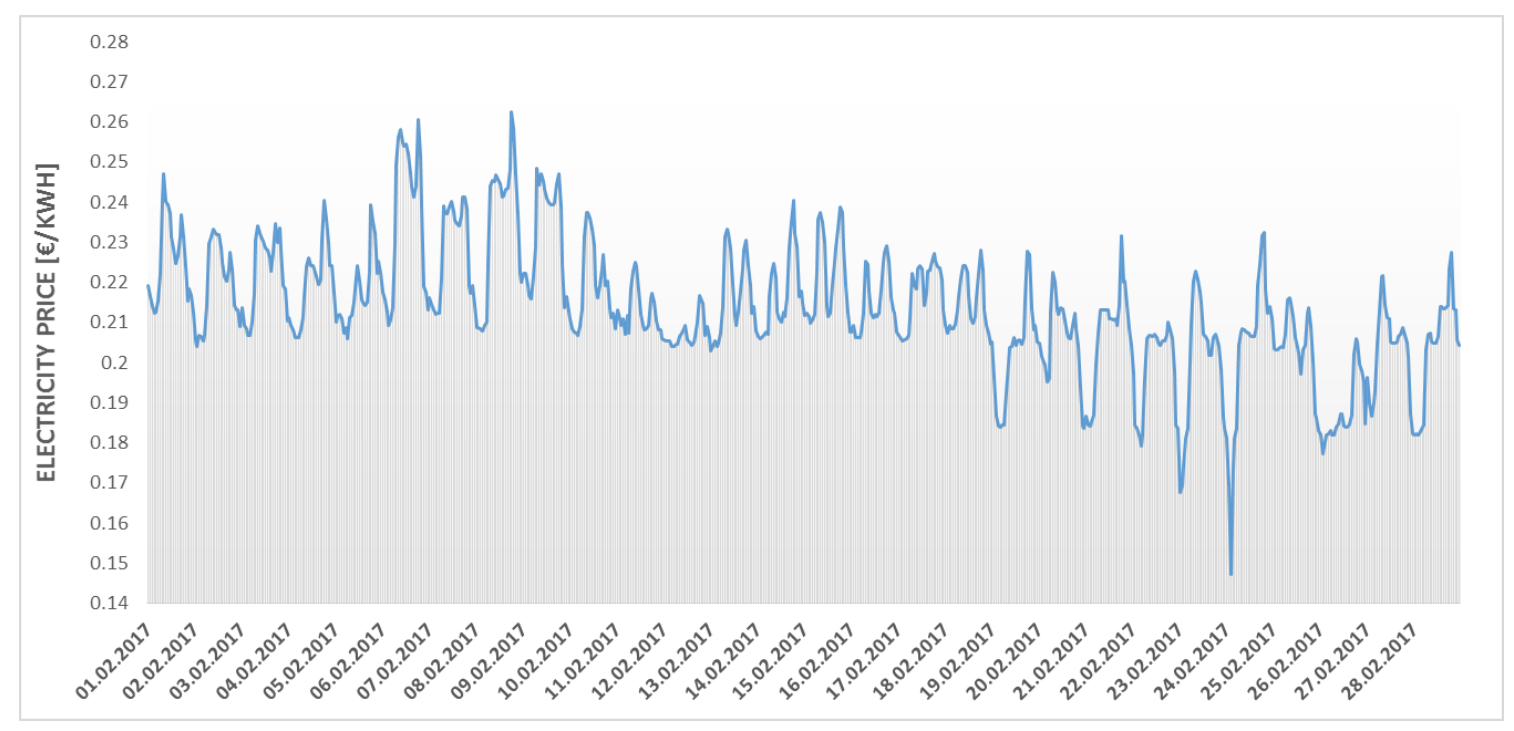

Figure 8: Electricity price profile during February 2017.

Several strategies have been considered. Some of them imply that the heat pump will work whenever the requirements of the normal operation control are fulfilled, but with different price thresholds (upper limits). Others will involve turning on the heat pump until that threshold is reached, but with varying indoor temperature $\left(T_{\text {air }}\right)$ limitations to avoid overheating. Three different scenarios with the same temperature setpoint $\left(20^{\circ} \mathrm{C}\right)$ but different temperature bands $\left(20 \pm 0{ }^{\circ} \mathrm{C}, 20 \pm 1{ }^{\circ} \mathrm{C}, 20 \pm 2{ }^{\circ} \mathrm{C}\right)$ will be considered. In them, a controller is in charge of turning the heat pump on or off depending on a signal. As soon as the lowest temperature of the band is reached $\left(20^{\circ} \mathrm{C}, 19{ }^{\circ} \mathrm{C}\right.$ and $18{ }^{\circ} \mathrm{C}$ respectively), the heat pump is activated. Nevertheless, it should be mentioned that although the heat pump is never activated once the upper part of the band is reached, slightly higher indoor temperatures might be achieved due to the influence of solar or internal gains. The opposite may also happen when there is ventilation in the household, reaching for a short time temperatures lower than the lowest part of the band. The list of the sixteen different devised strategies as well as setpoint scenarios is presented in Table 1. 


\begin{tabular}{|c|c|c|}
\hline $\begin{array}{l}\text { Setpoint } \\
\text { controls }\end{array}$ & $20 \pm 1{ }^{\circ} \mathrm{C}$ & $20 \pm 2{ }^{\circ} \mathrm{C}$ \\
\hline Strategy 1 & \multicolumn{2}{|c|}{ No limit. Static price of 0.22 [€/kWh]. HP works whenever necessary. } \\
\hline Strategy 2 & \multicolumn{2}{|c|}{ No limit. Day-ahead dynamic prices. HP works whenever necessary. } \\
\hline Strategy 3 & \multicolumn{2}{|c|}{ HP works whenever necessary, with a limit of $0.21[€ / \mathrm{kWh}]$} \\
\hline Strategy 4 & \multicolumn{2}{|c|}{ HP works whenever necessary, with a limit of $0.23[€ / \mathrm{kWh}]$} \\
\hline Strategy 5 & \multicolumn{2}{|c|}{ HP works whenever necessary, with a limit of average price of the day. } \\
\hline Strategy 6 & \multicolumn{2}{|c|}{ HP works whenever necessary, only during the night. } \\
\hline Strategy 7 & $\begin{array}{c}\text { HP works always with a limit of } 0.21 \\
{[€ / \mathrm{kWh}] \text { if } T_{\text {air }}<21^{\circ} \mathrm{C} .}\end{array}$ & $\begin{array}{l}\text { HP works always with a limit of } 0.21 \\
{[€ / \mathrm{kWh}] \text { if } \mathrm{T}_{\text {air }}<22^{\circ} \mathrm{C} \text {. }}\end{array}$ \\
\hline Strategy 8 & $\begin{array}{l}\text { HP works always with a limit of } 0.23 \\
{[€ / k W h] \text { if } T_{\text {air }}<21^{\circ} \mathrm{C} \text {. }}\end{array}$ & $\begin{array}{l}\text { HP works always with a limit of } 0.23 \\
{[€ / k W h] \text { if } T_{\text {air }}<22^{\circ} \mathrm{C} \text {. }}\end{array}$ \\
\hline Strategy 9 & $\begin{array}{l}\text { HP works always if price is lower than } \\
\text { average of the day and } T_{\text {air }}<21^{\circ} \mathrm{C} \text {. }\end{array}$ & $\begin{array}{l}\text { HP works always if price is lower than } \\
\text { average of the day and } T_{\text {air }}<22^{\circ} \mathrm{C} \text {. }\end{array}$ \\
\hline Strategy 10 & $\begin{array}{l}\text { HP works always during the night if } \mathrm{T}_{\text {air }} \\
\qquad<21^{\circ} \mathrm{C} \text {. }\end{array}$ & $\begin{array}{l}\text { HP works always during the night if } \mathrm{T}_{\text {air }} \\
\qquad<22^{\circ} \mathrm{C} .\end{array}$ \\
\hline Strategy 11 & $\begin{array}{c}\text { HP works always with a limit of } 0.21 \\
{[€ / k W h] \text { if } T_{\text {air }}<22^{\circ} \mathrm{C} \text {. }}\end{array}$ & $\begin{array}{c}\text { HP works always with a limit of } 0.21 \\
{[€ / k W h] \text { if Tair }<23^{\circ} \mathrm{C} \text {. }}\end{array}$ \\
\hline Strategy 12 & $\begin{array}{c}\text { HP works always with a limit of } 0.23 \\
{[€ / k W h] \text { if } T_{\text {air }}<22^{\circ} \mathrm{C} \text {. }}\end{array}$ & $\begin{array}{c}\text { HP works always with a limit of } 0.23 \\
{[€ / \mathrm{kWh}] \text { if } \mathrm{T}_{\text {air }}<23^{\circ} \mathrm{C} \text {. }}\end{array}$ \\
\hline Strategy 13 & $\begin{array}{l}\text { HP works always if price is lower than } \\
\text { average of the day and } T_{\text {air }}<22^{\circ} \mathrm{C} \text {. }\end{array}$ & $\begin{array}{l}\text { HP works always if price is lower than } \\
\text { average of the day and } T_{\text {air }}<23^{\circ} \mathrm{C} \text {. }\end{array}$ \\
\hline Strategy 14 & $\begin{array}{l}\text { HP works always during the night if } \mathrm{T}_{\text {air }} \\
\qquad 22^{\circ} \mathrm{C} \text {. }\end{array}$ & $\begin{array}{l}\text { HP works always during the night if } \mathrm{T}_{\text {air }} \\
\qquad<23^{\circ} \mathrm{C} .\end{array}$ \\
\hline Strategy 15 & $\begin{array}{l}\text { HP works always if price among the } \\
\text { lowest } 25 \% \text { of the day and } \mathrm{T}_{\text {air }}<21^{\circ} \mathrm{C} \text {. }\end{array}$ & $\begin{array}{l}\text { HP works always if price among the } \\
\text { lowest } 25 \% \text { of the day and } \mathrm{T}_{\text {air }}<22^{\circ} \mathrm{C} \text {. }\end{array}$ \\
\hline Strategy 16 & $\begin{array}{l}\text { HP works always if price among the } \\
\text { lowest } 25 \% \text { of the day and } \mathrm{T}_{\mathrm{air}}<22{ }^{\circ} \mathrm{C} \text {. }\end{array}$ & $\begin{array}{l}\text { HP works always if price among the } \\
\text { lowest } 25 \% \text { of the day and } \mathrm{T}_{\text {air }}<23^{\circ} \mathrm{C} \text {. }\end{array}$ \\
\hline
\end{tabular}

Table 1: Analyzed strategies.

The signal sent to the heat pump that the controller of our system uses for its activation acts in a similar way to the methods used by many studies, in which the setpoint temperatures are changed by a controller if the retail prices are higher than the customers' preset prices. It should be mentioned that as shown in the flowchart of Figure 5 , the system should always guarantee the provision of DHW in the household. This requirement was added to reflect the real system. Therefore, if the temperature of the DHW is below its threshold, the heat pump will be activated to heat the tank up to the desired temperature. During this time there will be no price threshold for the activation of the heat pump, and there will be no energy directed into the building. However, only the results concerning heating production will be considered from now on.

In order to show how these strategies work, some examples will be given. Figure 9 shows strategy 10 during a specific day for the scenario $20 \pm 0{ }^{\circ} \mathrm{C}$. The purpose of this strategy is to take advantage of the fact that electricity prices are normally lower during the night. In this alternative, the heat pump will always work during the night ( $0 \mathrm{AM}$ to $8 \mathrm{AM}$ ), but only if the indoor temperature of the building is 
below a certain threshold $\left(21^{\circ} \mathrm{C}\right.$ in the case of setpoint scenarios $20 \pm 0^{\circ} \mathrm{C}$ or $20 \pm 1{ }^{\circ} \mathrm{C}$, or $22{ }^{\circ} \mathrm{C}$ in $20 \pm 2$ ${ }^{\circ} \mathrm{C}$ ), so as to preheat the building with lower prices while avoiding to overheat it in the process.

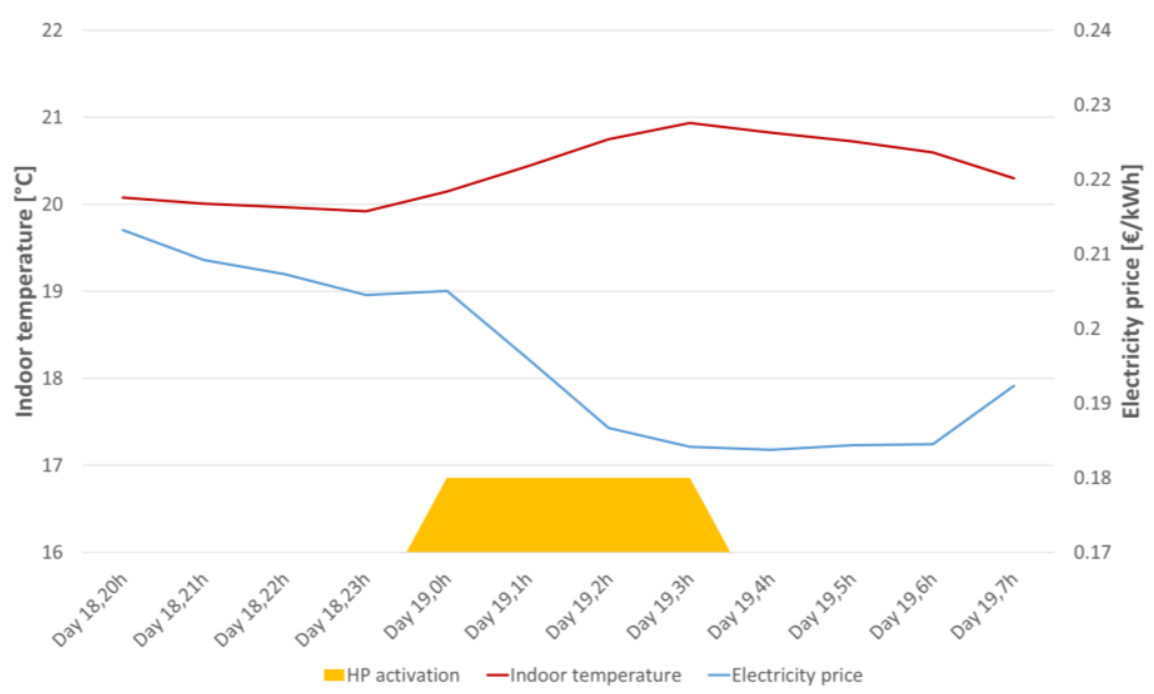

Figure 9: Operation mode of strategy 10 for setpoint scenario $20 \pm 0{ }^{\circ} \mathrm{C}$. Activating heat pump always during the night if $T_{\text {air }}<21^{\circ} \mathrm{C}$.

On the other hand, in strategy 7 the heat pump will always work if the price is lower than $21 \mathrm{c} € / \mathrm{kWh}$ and the temperature is lower than $21^{\circ} \mathrm{C}$, while in strategy 8 the price threshold is increased up to 23 $c € / k W h$. Conversely, strategy 15 maintains the same temperature threshold, but in this case the heat pump will always work if the electricity price is within the lowest $25 \%$ of the day. This strategy is possible due to the fact that the day-ahead market allows, as its name indicates, to know the prices the previous day. Figure 10 depicts the operation mode of these options, showing the indoor temperatures of the simulations as well as the price thresholds and the times at which the heat pumps were activated in each case.

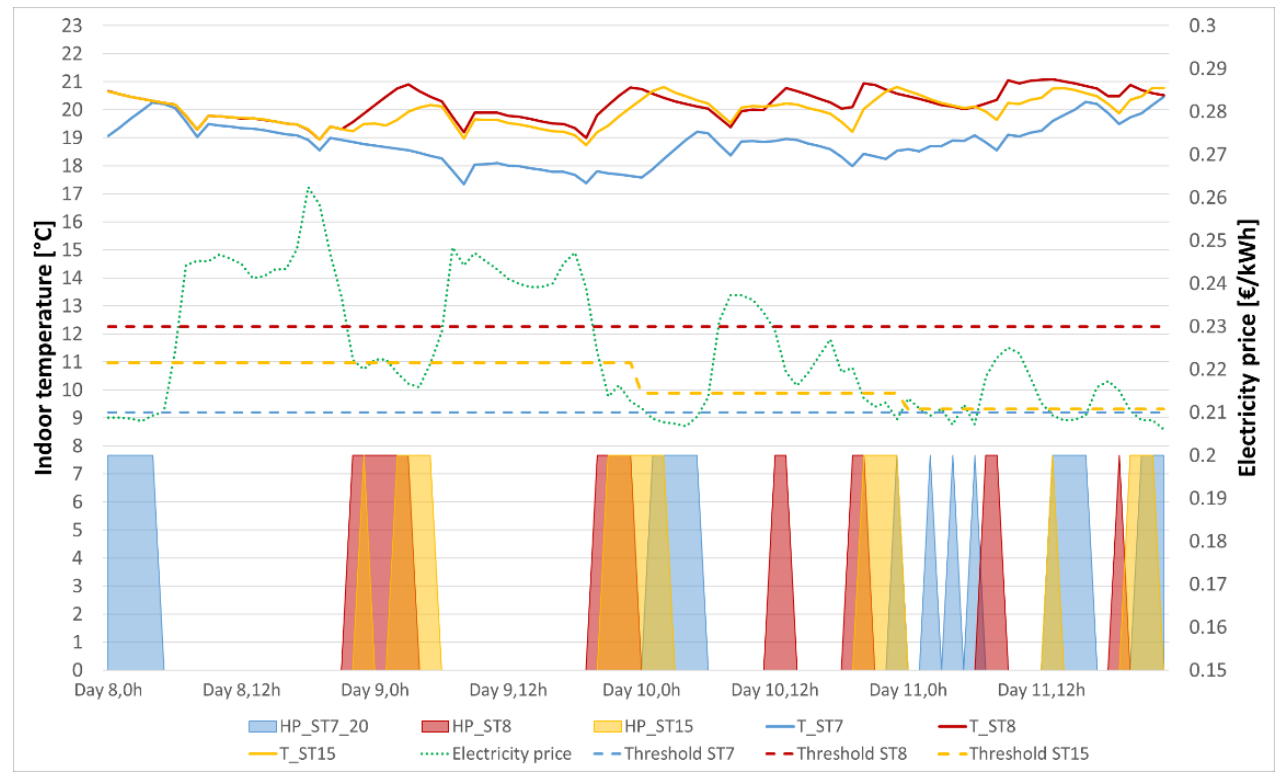

Figure 10: Example of different modes of operation depending on the strategy. 


\section{Analysis of results}

\subsection{Overview of the obtained results}

The outcomes of the simulations (16 different strategies for each of the 3 setpoint scenarios) are shown in

Table 2, Table 3 and Table 4. As previously mentioned, the calculated heat pump costs are only those when the heat pump is activated for heating the building, not the DHW tank (which has no price threshold to guarantee the availability of hot water). In this way, the comparisons and savings will only focus on the flexibility of the thermal storage capacity of the building itself.

In the following subsections we will analyze in detail each of the factors shown for the different strategies: cost savings, thermal comfort, heat pump consumption, PV self-consumption ratio, use during peak hours and a comparison between the three setpoint scenarios, which change their temperature bands. To avoid mixing different features, most of the comparisons will be done for each setpoint scenario independently, considering always their own strategy 1 as the base case in which the heat pump is activated whenever necessary according to the setpoint control of the system, with no restrictions and a typical constant price of $22 \mathrm{c} € / \mathrm{kWh}$.

\begin{tabular}{|c|c|c|c|c|c|c|}
\hline $\begin{array}{l}\text { Setpoint } \\
20 \pm 0\end{array}$ & $\begin{array}{l}\text { HP } \\
\text { Costs } \\
{[€]}\end{array}$ & $\begin{array}{c}\mathrm{Hp} \\
\text { consumption } \\
{[\mathrm{kWh}]}\end{array}$ & $\begin{array}{c}\text { PV Self- } \\
\text { consumption [\%] }\end{array}$ & $\begin{array}{c}\text { Sum of excess } \\
\text { temperature } \\
\text { degree-hours } \\
<20^{\circ} \mathrm{C} \\
\end{array}$ & $\begin{array}{l}\text { Sum of excess } \\
\text { temperature } \\
\text { degree-hours } \\
>20^{\circ} \mathrm{C} \\
\end{array}$ & $\begin{array}{c}\text { Use during peak } \\
\text { hours [\%] }\end{array}$ \\
\hline Strategy 1 & 44.8 & 203.4 & $33.6 \%$ & 22.3 & 227.9 & $40.6 \%$ \\
\hline Strategy 2 & 44.5 & 203.4 & $33.6 \%$ & 22.3 & 227.9 & $40.6 \%$ \\
\hline Strategy 3 & 37.1 & 184.2 & $35.5 \%$ & 242.9 & 95.9 & $5.0 \%$ \\
\hline Strategy 4 & 41.8 & 198.5 & $33.8 \%$ & 49.2 & 179.5 & $20.0 \%$ \\
\hline Strategy 5 & 37.9 & 184.8 & $34.3 \%$ & 69.3 & 104.1 & $0.0 \%$ \\
\hline Strategy 6 & 38.4 & 185.2 & $34.3 \%$ & 73.4 & 123.5 & $11.6 \%$ \\
\hline Strategy 7 & 42.1 & 206.8 & $35.7 \%$ & 176.3 & 296.1 & $3.0 \%$ \\
\hline Strategy 8 & 45.1 & 210.1 & $36.9 \%$ & 33.9 & 400.9 & $26.3 \%$ \\
\hline Strategy 9 & 42.0 & 201.7 & $36.0 \%$ & 40.0 & 342.7 & $0.0 \%$ \\
\hline Strategy 10 & 42.7 & 208.4 & $33.2 \%$ & 24.7 & 350.8 & $5.3 \%$ \\
\hline Strategy 11 & 46.0 & 218.3 & $35.4 \%$ & 123.7 & 558.4 & $0.0 \%$ \\
\hline Strategy 12 & 48.7 & 229.5 & $37.9 \%$ & 16.5 & 706.1 & $16.4 \%$ \\
\hline Strategy 13 & 47.8 & 230.1 & $36.2 \%$ & 17.7 & 737.5 & $0.0 \%$ \\
\hline Strategy 14 & 46.7 & 227.9 & $32.4 \%$ & 15.5 & 645.2 & $4.3 \%$ \\
\hline Strategy 15 & 40.7 & 200.5 & $35.2 \%$ & 58.6 & 315.8 & $0.0 \%$ \\
\hline Strategy 16 & 45.1 & 222.6 & $35.3 \%$ & 37.8 & 630.8 & $0.0 \%$ \\
\hline
\end{tabular}

Table 2: Obtained results for the setpoint strategy $20 \pm 0{ }^{\circ} \mathrm{C}$. 


\begin{tabular}{|c|c|c|c|c|c|c|}
\hline $\begin{array}{l}\text { Setpoint } \\
20 \pm 1\end{array}$ & $\begin{array}{l}\text { HP Costs } \\
{[€]}\end{array}$ & $\begin{array}{c}\mathrm{Hp} \\
\text { consumption } \\
{[\mathrm{kWh}]}\end{array}$ & $\begin{array}{c}\text { PV Self- } \\
\text { consumption [\%] }\end{array}$ & $\begin{array}{l}\text { Sum of excess } \\
\text { temperature } \\
\text { degree-hours } \\
<20^{\circ} \mathrm{C}\end{array}$ & $\begin{array}{l}\text { Sum of excess } \\
\text { temperature } \\
\text { degree-hours } \\
>20^{\circ} \mathrm{C}\end{array}$ & $\begin{array}{c}\text { Use during peak } \\
\text { hours [\%] }\end{array}$ \\
\hline Strategy 1 & 42.2 & 191.7 & $39.9 \%$ & 82.9 & 164.2 & $43.0 \%$ \\
\hline Strategy 2 & 42.7 & 191.7 & $39.9 \%$ & 82.9 & 164.2 & $43.0 \%$ \\
\hline Strategy 3 & 36.0 & 178.2 & $37.4 \%$ & 287.6 & 167.8 & $0.0 \%$ \\
\hline Strategy 4 & 41.2 & 194.6 & $39.2 \%$ & 100.6 & 205.8 & $15.6 \%$ \\
\hline Strategy 5 & 39.1 & 187.7 & $38.2 \%$ & 107.3 & 181.4 & $0.0 \%$ \\
\hline Strategy 6 & 39.4 & 193.7 & $34.8 \%$ & 119.6 & 207.1 & $5.8 \%$ \\
\hline Strategy 7 & 35.5 & 175.7 & $37.4 \%$ & 317.2 & 149.5 & $0.0 \%$ \\
\hline Strategy 8 & 39.7 & 186.9 & $39.8 \%$ & 94.4 & 144.1 & $12.7 \%$ \\
\hline Strategy 9 & 38.8 & 186.2 & $38.4 \%$ & 114.9 & 139.7 & $0.0 \%$ \\
\hline Strategy 10 & 38.5 & 190.0 & $35.0 \%$ & 121.6 & 158.5 & $3.4 \%$ \\
\hline Strategy 11 & 40.2 & 197.8 & $35.7 \%$ & 231.1 & 336.1 & $0.0 \%$ \\
\hline Strategy 12 & 44.6 & 211.5 & $38.8 \%$ & 72.6 & 419.2 & $16.3 \%$ \\
\hline Strategy 13 & 45.7 & 222.0 & $33.9 \%$ & 68.9 & 495.8 & $0.0 \%$ \\
\hline Strategy 14 & 45.7 & 224.6 & $33.4 \%$ & 81.7 & 499.6 & $8.0 \%$ \\
\hline Strategy 15 & 38.8 & 191.8 & $37.2 \%$ & 117.8 & 169.3 & $0.0 \%$ \\
\hline Strategy 16 & 44.1 & 219.8 & $34.3 \%$ & 84.8 & 454.8 & $0.0 \%$ \\
\hline
\end{tabular}

Table 3: Obtained results for the setpoint strategy $20 \pm 1{ }^{\circ} \mathrm{C}$.

\begin{tabular}{|c|c|c|c|c|c|c|}
\hline $\begin{array}{l}\text { Setpoint } \\
20 \pm 2\end{array}$ & $\begin{array}{l}\text { HP Costs } \\
{[€]}\end{array}$ & $\begin{array}{c}\mathrm{Hp} \\
\text { consumption } \\
{[\mathrm{kWh}]}\end{array}$ & $\begin{array}{c}\text { PV Self- } \\
\text { consumption [\%] }\end{array}$ & $\begin{array}{l}\text { Sum of excess } \\
\text { temperature } \\
\text { degree-hours } \\
<20^{\circ} \mathrm{C} \\
\end{array}$ & $\begin{array}{l}\text { Sum of excess } \\
\text { temperature } \\
\text { degree-hours } \\
>20^{\circ} \mathrm{C}\end{array}$ & $\begin{array}{c}\text { Use during peak } \\
\text { hours [\%] }\end{array}$ \\
\hline Strategy 1 & 41.7 & 189.5 & $39.4 \%$ & 273.7 & 238.5 & $11.4 \%$ \\
\hline Strategy 2 & 39.1 & 189.5 & $39.4 \%$ & 273.7 & 238.5 & $11.4 \%$ \\
\hline Strategy 3 & 32.9 & 167.3 & $38.9 \%$ & 531.9 & 166.9 & $1.9 \%$ \\
\hline Strategy 4 & 39.6 & 190.9 & $40.5 \%$ & 230.7 & 238.4 & $5.2 \%$ \\
\hline Strategy 5 & 40.5 & 197.5 & $34.8 \%$ & 284.8 & 279.8 & $0.0 \%$ \\
\hline Strategy 6 & 34.4 & 168.9 & $36.0 \%$ & 295.0 & 227.3 & $3.9 \%$ \\
\hline Strategy 7 & 32.9 & 167.3 & $39.0 \%$ & 536.4 & 178.7 & $1.9 \%$ \\
\hline Strategy 8 & 39.6 & 190.9 & $40.5 \%$ & 238.0 & 224.8 & $5.2 \%$ \\
\hline Strategy 9 & 40.5 & 197.5 & $34.8 \%$ & 284.8 & 279.8 & $0.0 \%$ \\
\hline Strategy 10 & 33.7 & 165.3 & $36.2 \%$ & 309.2 & 207.2 & $4.0 \%$ \\
\hline Strategy 11 & 31.8 & 157.2 & $38.6 \%$ & 510.3 & 258.5 & $0.0 \%$ \\
\hline Strategy 12 & 44.9 & 213.9 & $34.6 \%$ & 232.0 & 446.7 & $10.3 \%$ \\
\hline Strategy 13 & 37.6 & 184.9 & $35.5 \%$ & 251.8 & 358.5 & $0.0 \%$ \\
\hline Strategy 14 & 44.7 & 217.1 & $33.7 \%$ & 250.0 & 404.4 & $8.5 \%$ \\
\hline Strategy 15 & 37.8 & 187.0 & $36.5 \%$ & 303.6 & 262.8 & $0.0 \%$ \\
\hline Strategy 16 & 37.4 & 188.1 & $36.3 \%$ & 251.6 & 329.2 & $0.0 \%$ \\
\hline
\end{tabular}

Table 4: Obtained results for the setpoint strategy $20 \pm 2{ }^{\circ} \mathrm{C}$. 


\subsection{Cost savings}

The costs of running the heat pump to provide heating for the building for all the options considered are shown in Figure 11. As it can be seen, among the lowest costs for the three setpoint scenarios are strategies 3, 5 and 7 with given fixed price limits for activation, which can achieve savings up to $21 \%$ compared to their base case (depending on the setpoint scenario). Conversely, strategies 12,13 and 14 (in which the heat pump always works with certain temperature and price thresholds) are among the most expensive options.

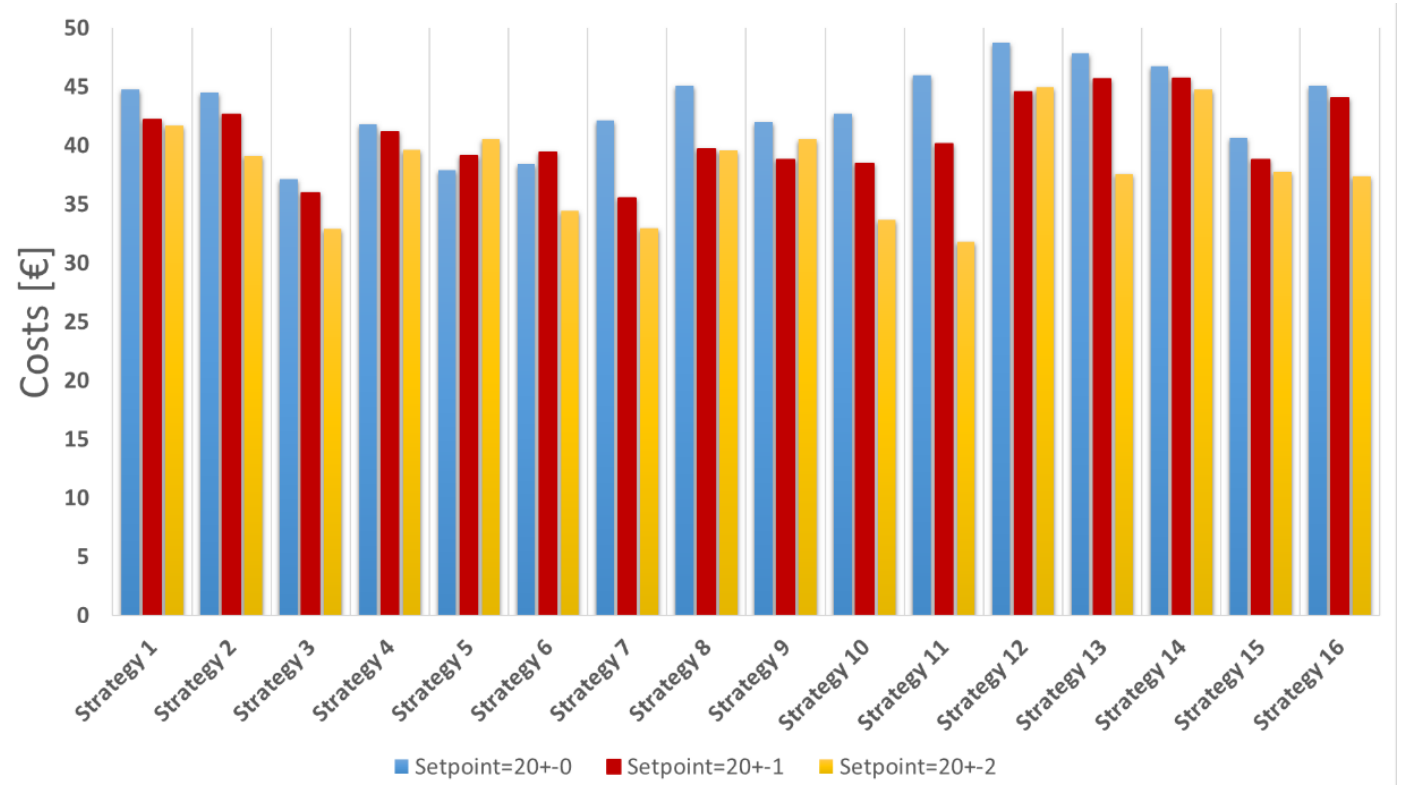

Figure 11: Comparison of heat pump monthly cost for heating electricity.

There is however a reason behind these results: due to the price thresholds, the heat pump might not be activated when needed, or it may be activated more often than necessary. Therefore, in order to choose the optimal strategies, the focus cannot be merely in costs.

\subsection{Thermal comfort}

To detect comfort problems, it is of paramount importance to check the indoor temperatures achieved by each of the strategies. Figure 12 shows a comparison of the daily average temperatures for some strategies of the $20 \pm 0{ }^{\circ} \mathrm{C}$ setpoint scenario. It becomes apparent that for instance in strategy 3 , among the best when focusing on costs, the heat pump is not activated often enough so as to keep an appropriate indoor comfort. The reason is that its price threshold is too low, so there are some periods in which the heat pump would not be activated at all. This could be expected because the limits for strategy 3 are only costs, and not temperature. Conversely, strategy 13 (HP works always if price is lower than average and $\mathrm{T}_{\text {air }}<22^{\circ} \mathrm{C}$ ) behaves in the opposite way: much higher indoor temperatures than in the base case are achieved, therefore increasing the heat pump consumption and costs. However, some strategies such as 4,5 or 15 are capable of maintaining acceptable indoor temperatures. 


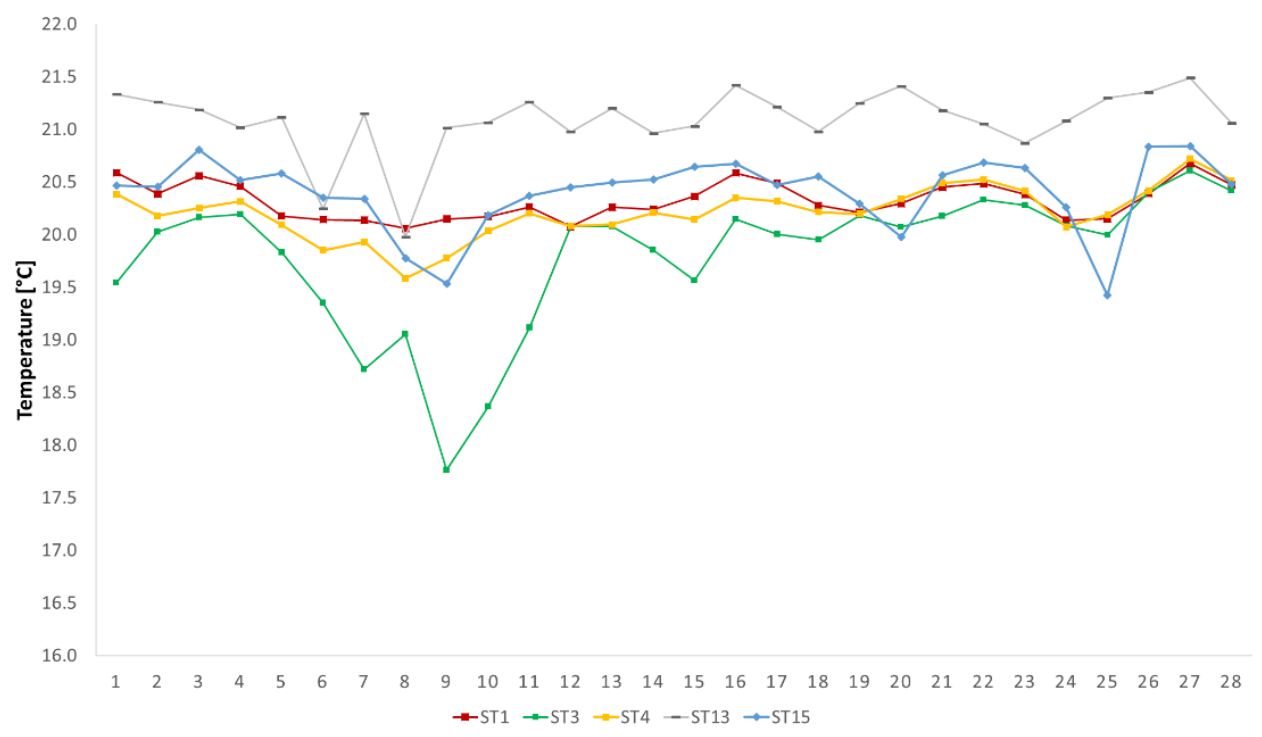

Figure 12: Comparison of the daily temperature of different strategies. Case $20 \pm 0{ }^{\circ} \mathrm{C}$.

Figure 13 presents the sum of excess of degree-hours during the whole month for every strategy and setpoint scenario. Positive values mean the sum of excess degree-hours above $20^{\circ} \mathrm{C}$, while negative values mean the sum below $20^{\circ} \mathrm{C}$. It is evident that strategies 3,7 and 11 (which have a low price threshold of $21 \mathrm{c} € / \mathrm{kWh}$ ) are not capable of reaching $20{ }^{\circ} \mathrm{C}$ during many hours of the month, while strategies $11,12,13,14$ and 16 (with less restrictions for the HP operation) produce too much overheating.

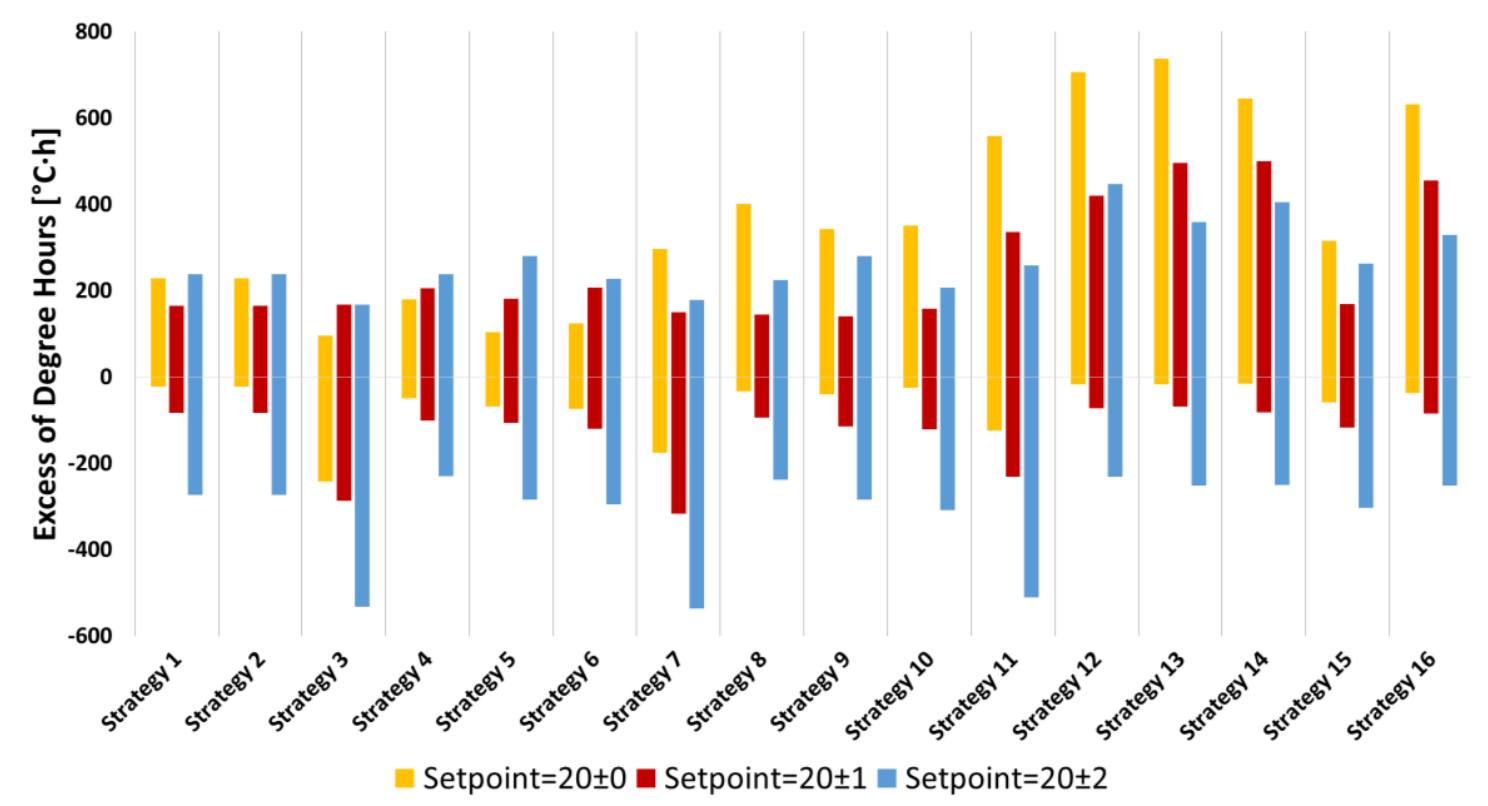

Figure 13: Comparison of the amount of excess degree-hours. Positive values show $>20^{\circ} \mathrm{C}$ and negative values $<20^{\circ} \mathrm{C}$. 


\subsection{Thermal comfort VS cost savings}

As we have seen, in economic terms among the best strategies are for example 3 and 7, but they cannot achieve an acceptable indoor comfort. On the other hand, strategy 5 whose price threshold is the average of the current day, can achieve savings up to $15.3 \%$ for the setpoint scenario $20 \pm 0{ }^{\circ} \mathrm{C}$, without compromising noticeably the thermal comfort. Strategies 12,13 and 14, among the most convenient related to the sum of excess of degree-hours below $20^{\circ} \mathrm{C}$, cause too much overheating and have even negative savings due to the excessive increase of the heat pump use (see Figure 14). These results illustrate the importance of considering both aspects when choosing an optimal DR strategy.

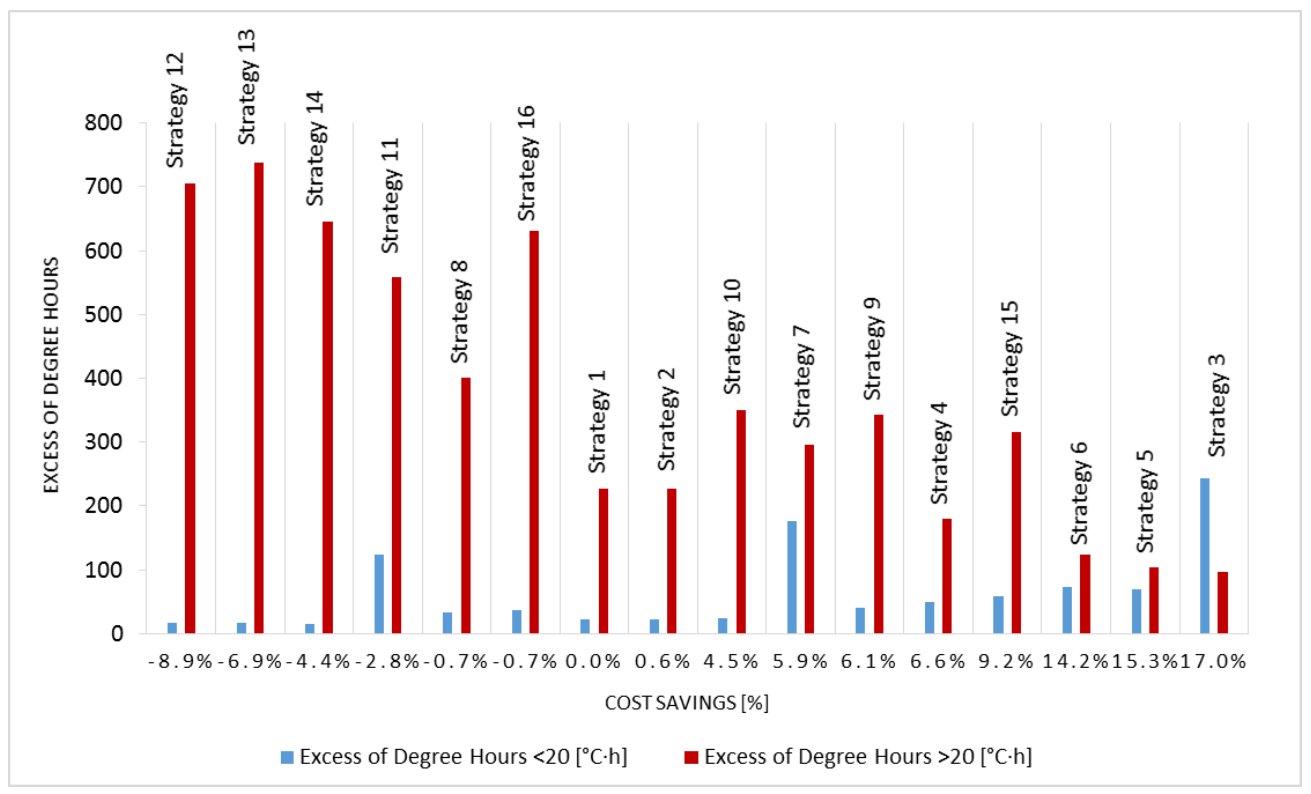

Figure 14: Upper and lower temperature excess hours versus cost savings. Case $20 \pm 0{ }^{\circ} \mathrm{C}$. Positive cost savings mean less costs than the base case.

\subsection{Heat pump consumption}

The heat pump consumption is strongly linked to the cost savings and the thermal comfort. The strategies which show in general lower HP consumption are 3, 5 and 7 (low price thresholds), while the ones showing higher consumption are 11,12,13, 14 and 16 (less restrictions for the HP operation). Another conclusion of the setpoint scenario $20 \pm 0{ }^{\circ} \mathrm{C}$ for example is the fact that if no negative deviation from the setpoint is allowed, i.e nearly no $<20^{\circ} \mathrm{C}$ excess degree-hours, then the HP consumption is always increased. That is the case of using strategy 10 (HP works always during the night if $\mathrm{T}_{\text {air }}<21^{\circ} \mathrm{C}$ ) instead of the base case. As stated in the literature review, the reason is that increasing the temperatures above its normal setpoint temperature (from 20 to 21 or $22^{\circ} \mathrm{C}$ ) in these strategies results in an increase of the energy losses of the building. Therefore, although there may be cost savings, the heat pump consumption is increased. 


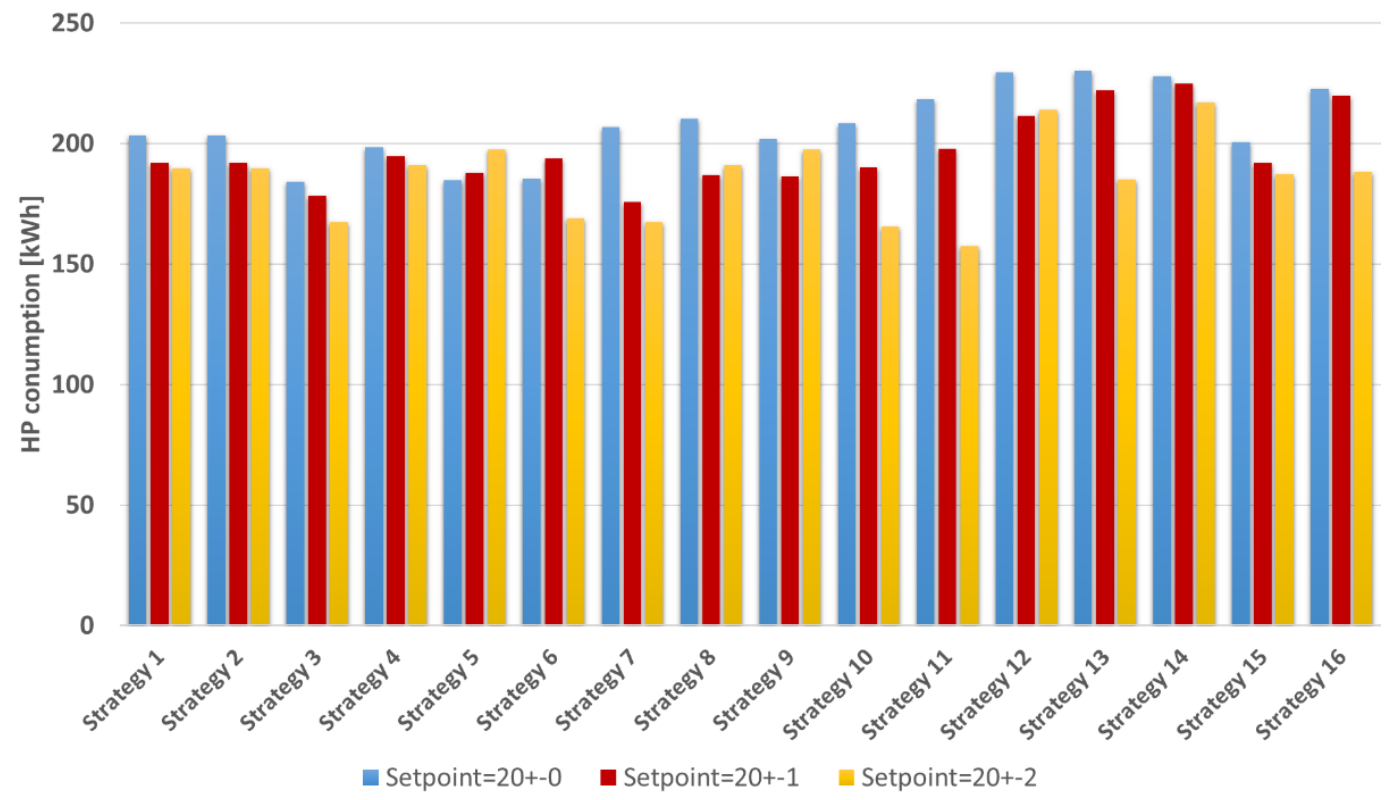

Figure 15: Comparison of the heat pump consumptions.

\subsection{Self-consumption ratios}

Another interesting outcome of the present study is to quantify the way in which the different heat pump operating strategies affect the ratio of self-consumption of the household (shown in Figure 16 for all the strategies and scenarios). The PV self-consumption ratio is influenced by the state of charge of the battery as well as the time-dependent match between PV production and HP consumption. In general, most of the strategies use the electricity during non-peak periods, which are not normally during the day (when there is PV production). Therefore, the heat pump which is the main electricity consumption contributor would be rarely used at the same time as the electricity is produced by the PV panels. As a result, the self-consumption ratio could decrease. The amount of decrease would then depend on the capacity of the electric battery. However, as we can see there are only slight variations, always lower than $8 \%$ among all the different strategies.

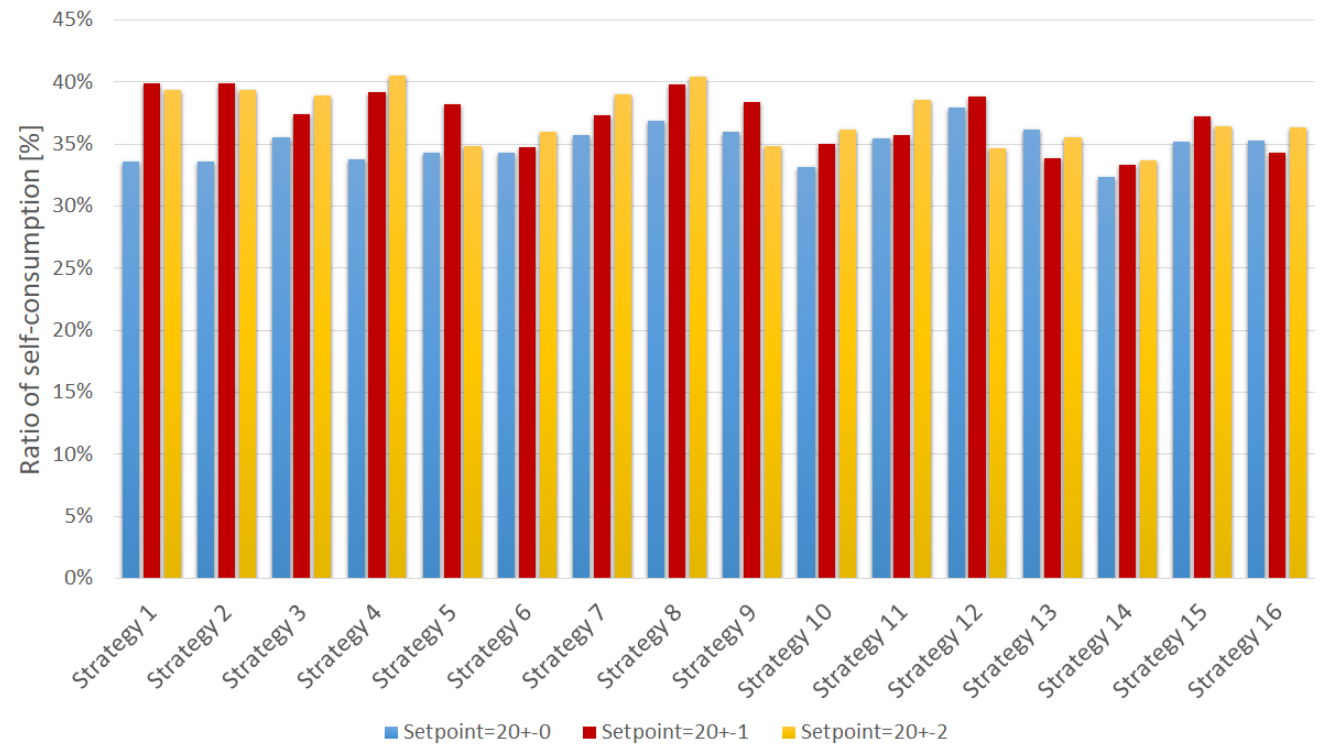

Figure 16: Comparison of ratios of self-consumption. 


\subsection{Use during peak hours}

One of the main reasons of the existence of DR, as stated in the literature review, is the benefits it can bring with regards to the reduction of peak demand, which might cause grid stress and entail an increase of the use of less efficient power plants. To illustrate the influence of the chosen strategies on peak reduction, Figure 17 shows the percentage of heat pump use during peak hours. In this case, the peak hours have been defined as the use of the HP during hours with electricity costs above $75 \%$ of the maximum price of the day.

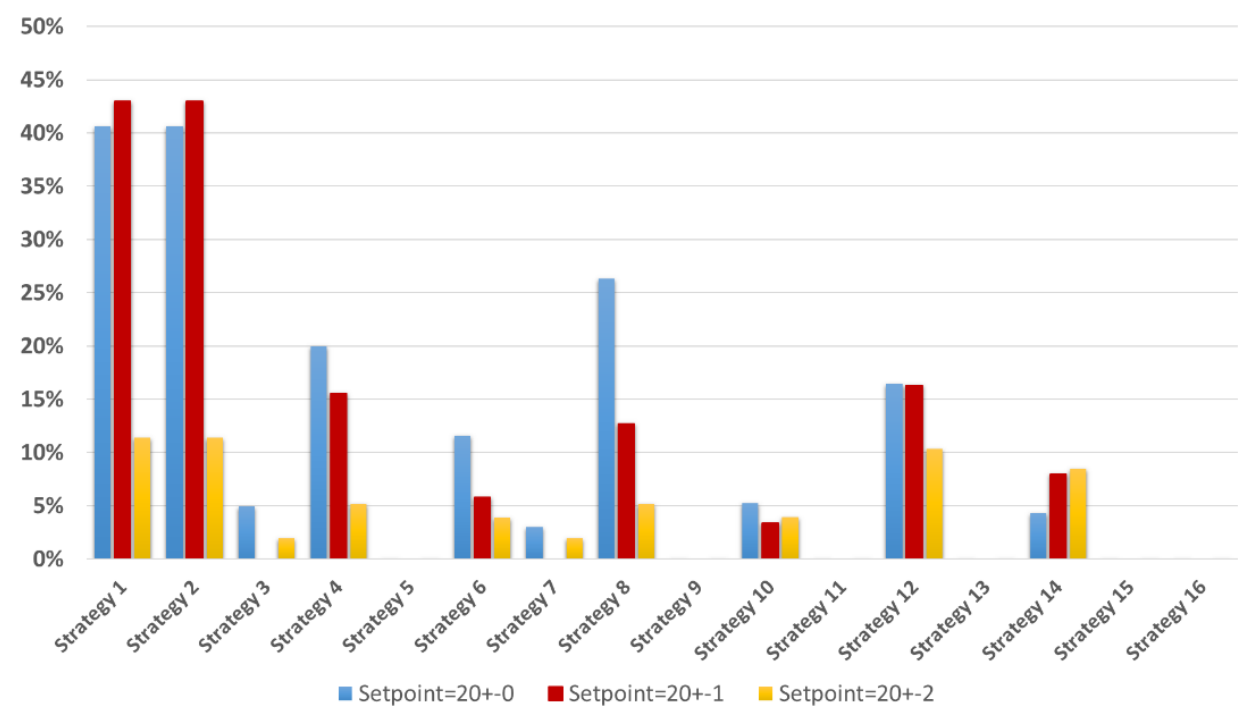

Figure 17: Percentage of HP use during peak hours [\%].

As we can see, the base case strategies have the highest percentages of heat pump use during peak hours. The obvious reason is that there is no time restriction for their use, and no price thresholds. The strategies which have a price threshold of $23 \mathrm{c€} / \mathrm{kWh}(4,8$ and 12) are the ones with a highest percentage of use during peak hours among the proposed strategies, since the threshold is quite high and the heat pump is used during peak hours more often. On the other hand, strategies 3 and 7 (price threshold of $21 \mathrm{c} € / \mathrm{kWh}$ ) use the heat pumps only rarely during peak times, and the same happens with strategies 6, 10 and 14, which only allow their use during the night. For the rest of the strategies, we can observe that the heat pump is never used during peak hours, showing how beneficial they could be when the focus is on peak reduction.

\subsection{Comparison between setpoint temperature bands}

It is difficult to observe a clear tendency when changing the temperature bands. The comparison depends strongly on the price and temperature thresholds imposed in the strategies, since the indoor temperatures reached will influence the heat pump consumption and therefore the outcomes of this comparison. Generally, it can be said that the higher the temperature band the lower the consumption of the heat pump and the higher the cost savings. This is mainly due to the fact that higher and lower room temperatures than the setpoint are allowed, inducing longer free-floating periods. Also, higher temperature bands mean lower activations of the HP, thus avoiding short cycling. That is the case of most strategies, among them the base case for example: the scenario $20 \pm 1$ has $5.8 \%$ of HP consumption savings compared to $20 \pm 0$, and $20 \pm 2$ has $6.8 \%$. In addition, an increase in the temperature band means in most cases a higher ratio of self-consumption, although that is not the case of some strategies due to the reasons stated in Section 3.6. 


\subsection{Optimal strategies}

A good compromise between thermal comfort and cost savings needs to be achieved so as to choose the most interesting strategies, which vary depending on the setpoint scenario. Moreover, the reduction of the heat pump consumption, use during peak hours and increase of self-consumption ratio should be also borne in mind, since they entail environmental benefits. A summary of the best considered strategies for each setpoint scenario is shown in Table 5. It should be noted that due to the interaction of different aspects, the criteria for the optimal strategies are somewhat subjective.

\begin{tabular}{|c|c|c|c|c|c|c|c|c|c|}
\hline \\
\hline & & $\begin{array}{c}\text { HP } \\
\text { costs } \\
{[€]}\end{array}$ & $\begin{array}{c}\text { Cost } \\
\text { savings } \\
{[\%]} \\
\text { (compared } \\
\text { to own } \\
\text { base } \\
\text { scenario) }\end{array}$ & $\begin{array}{c}\text { Cost } \\
\text { savings } \\
{[\%]} \\
\text { (compared } \\
\text { to } 20 \pm 0 \\
\text { base } \\
\text { scenario) }\end{array}$ & $\begin{array}{c}\text { Sum of } \\
\text { excess } \\
\text { temperature } \\
\text { degree- } \\
\text { hours } \\
<20^{\circ} \mathrm{C}\end{array}$ & $\begin{array}{c}\text { Sum of } \\
\text { excess } \\
\text { temperature } \\
\text { degree- } \\
\text { hours } \\
>20^{\circ} \mathrm{C}\end{array}$ & $\begin{array}{l}\text { HP cons. } \\
\text { savings } \\
\text { (compared } \\
\text { to own } \\
\text { base } \\
\text { scenario) }\end{array}$ & $\begin{array}{c}\text { Ratio of self- } \\
\text { consumption } \\
{[\%]}\end{array}$ & $\begin{array}{c}\text { Percentage } \\
\text { of use } \\
\text { during } \\
\text { peak hours } \\
\text { [\%] }\end{array}$ \\
\hline \multirow{3}{*}{$\begin{array}{l}\text { Setpoint } \\
20 \pm 0\end{array}$} & $\begin{array}{c}\text { Strategy } 1 \\
\text { (base case) }\end{array}$ & 44.8 & $0 \%$ & $0 \%$ & 22.2 & 227.9 & $0.0 \%$ & $33.6 \%$ & $40.6 \%$ \\
\hline & Strategy 5 & 37.9 & $15.3 \%$ & $15.3 \%$ & 69.3 & 104.1 & $9.2 \%$ & $34.3 \%$ & $0 \%$ \\
\hline & Strategy 15 & 40.7 & $9.2 \%$ & $9.2 \%$ & 58.6 & 315.8 & $1.4 \%$ & $35.2 \%$ & $0 \%$ \\
\hline \multirow[t]{2}{*}{$\begin{array}{l}\text { Setpoint } \\
20 \pm 1\end{array}$} & Strategy 5 & 39.1 & $7.3 \%$ & $12.7 \%$ & 107.3 & 181.4 & $2.1 \%$ & $38.2 \%$ & $0 \%$ \\
\hline & Strategy 8 & 39.7 & $5.9 \%$ & $11.3 \%$ & 94.4 & 144.1 & $2.5 \%$ & $39.8 \%$ & $12.7 \%$ \\
\hline \multirow[t]{2}{*}{$\begin{array}{c}\text { Setpoint } \\
20 \pm 2\end{array}$} & Strategy 6 & 34.4 & $17.5 \%$ & $23.1 \%$ & 295.0 & 227.3 & $10.9 \%$ & $36.0 \%$ & $3.9 \%$ \\
\hline & Strategy 10 & 33.7 & $19.2 \%$ & $24.7 \%$ & 309.2 & 207.2 & $12.8 \%$ & $36.2 \%$ & $4.0 \%$ \\
\hline
\end{tabular}

Table 5: Selection of the optimal strategies.

Several conclusions can be drawn from the selection which has been made. Compared to the base case (the way in which the real household is controlled), it is possible to achieve around $15 \%$ of cost savings for the energy used to heat the building, without changing the setpoint temperature band, and without sacrificing noticeably the thermal comfort. This involves using strategy 5 , in which the heat pump will work when necessary, but only if the price is below the average of the current day. As a result, the HP consumption is $9 \%$ lower, the self-consumption ratio increases by $1 \%$ and there is no use of the HP during peak hours. Strategy 15 (turning on the HP always if the price is within the lowest $25 \%$ of the current day and the indoor temperature is below $21^{\circ} \mathrm{C}$ ) can also achieve $9 \%$ savings with almost the same heat pump consumption as the base case and no use during peak hours, although with a bit more of overheating.

On the other hand, increasing the temperature band up to $\pm 1{ }^{\circ} \mathrm{C}$ would increase the self-consumption ratios and achieve around $12 \%$ of cost savings by using strategies 5 or 8 . However, this involves obviously an increase of the $<20^{\circ} \mathrm{C}$ excess degree-hours. Last of all, using the setpoint scenario $20 \pm 2$ ${ }^{\circ} \mathrm{C}$ would allow to use strategies 6 or 10 , which achieve around $24 \%$ of cost savings compared to the base case in $20 \pm 0^{\circ} \mathrm{C}$, also reducing the HP consumption and the use during peak hours, and increasing the ratio of self-consumption. The average daily temperatures of some of these optimal strategies are shown in Figure 18. 


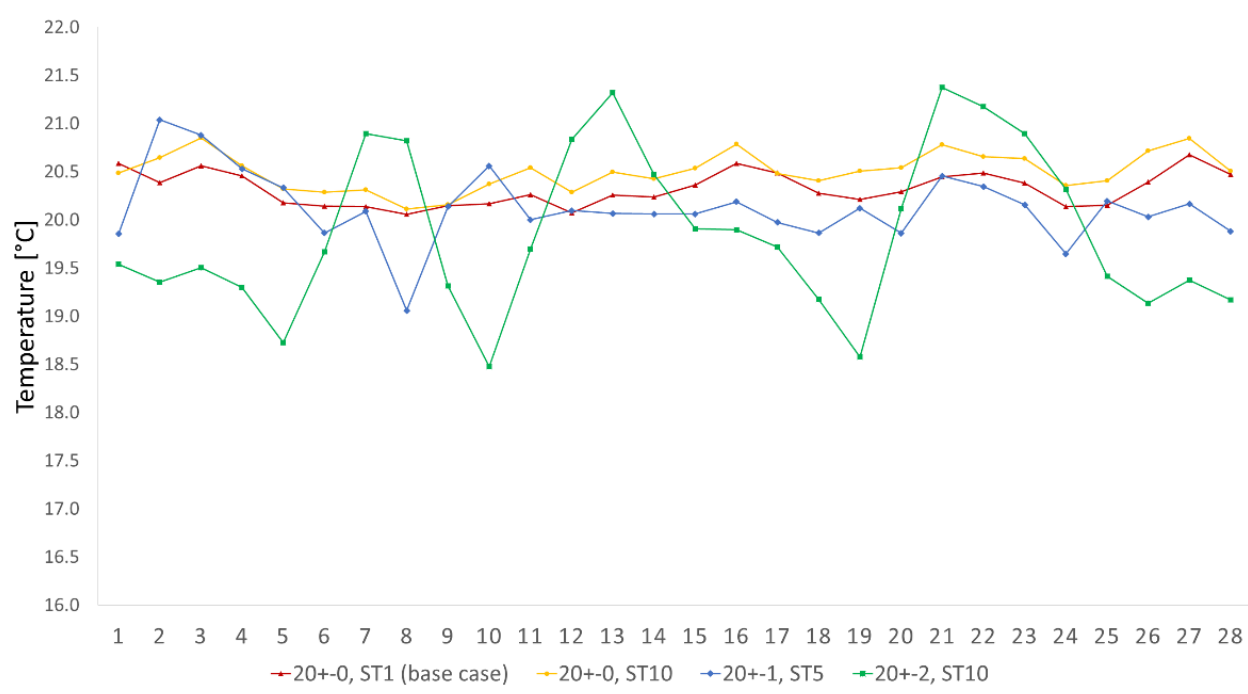

Figure 18: Average daily temperature of the selected strategies.

\section{Conclusions}

The present work has analyzed the benefits of DR strategies for heat pumps incentivized by day-ahead pricing signals. A recently constructed plus energy district in Southern Germany was taken as a case study, with monitoring data available for decentral heat pumps connected to a cold district heating network. Several dynamic pricing alternatives which depend on temperature and price thresholds were evaluated to control the operation of the heat pump in one of the buildings. This was done with the purpose of finding those strategies that could lead to significant cost savings while maintaining an acceptable thermal comfort.

Evidence has been obtained on the importance of choosing the correct price thresholds when using dynamic pricing strategies for DR purposes. The results show that fixed price thresholds are not the best option, since the high variations of the market could result in reduced activations of the heat pump, with the consequent thermal comfort losses. Instead, dynamic thresholds depending on the variations within the day are a better alternative.

Savings up to $25 \%$ were achieved by using optimal strategies, also resulting in increases of selfconsumption ratios for the given photovoltaic systems and without sacrificing noticeably the thermal comfort of the occupants. Apart from the previously mentioned benefits, the proposed optimal strategies achieved significant peak reductions on the grid, since the heat pumps were mostly used during low-peak periods.

These strategies also highlight the importance of knowing how much the users are willing to sacrifice their comfort to achieve savings. In addition, it is vital to take into account the heat pump energy consumption when choosing the best option, since overheating the building above its normal setpoint temperature results in energy losses, therefore increasing the energy consumption unless the sum of excess degree-hours below the setpoint temperature is also noticeable. In the case of having local renewable generation, the self-consumption ratios should always be considered, since their increase is also valuable to relieve the electricity grids.

The outcomes of the present study have shown the great impact that the use of heat pumps and the thermal storage capacity of buildings may have by using dynamic pricing strategies within a DR framework. The importance of looking at all the implications of these strategies was also demonstrated, since it was proven that the decisions to choose the optimal strategies should not rely solely on one of many potentially contradictory aspects. 


\section{Acknowledgments}

The authors would like to take this opportunity to thank the University of Seville for its financial support through the US Research Plan V (VPPI-US). The authors would also like to thank the researchers from HFT Stuttgart involved in the Wüstenrot demonstration project, especially Marcus Brennenstuhl from the Sim4Blocks project team for providing measurement data. The Sim4Blocks research, where demand response strategies are compared in three different European sites, has received funding from the European Union's Horizon 2020 research and innovation programme under grant agreement No 695965. 


\section{$5 \quad$ References}

[1] Yin R, Kara EC, Li Y, DeForest N, Wang K, Yong T, et al. Quantifying flexibility of commercial and residential loads for demand response using setpoint changes. Appl Energy 2016;177:149-64. doi:10.1016/j.apenergy.2016.05.090.

[2] Singla S, Keshav S. Demand response through a temperature setpoint market in Ontario. 2012 IEEE 3rd Int Conf Smart Grid Commun SmartGridComm 2012 2012:103-8. doi:10.1109/SmartGridComm.2012.6485967.

[3] Hoogvliet TW, Litjens GBMA, van Sark WGJHM. Provision of regulating- and reserve power by electric vehicle owners in the Dutch market. Appl Energy 2017;190:1008-19. doi:10.1016/j.apenergy.2017.01.006.

[4] Chassin DP, Stoustrup J, Agathoklis P, Djilali N. A new thermostat for real-time price demand response: Cost, comfort and energy impacts of discrete-time control without deadband. Appl Energy 2015;155:816-25. doi:10.1016/j.apenergy.2015.06.048.

[5] Aduda KO, Labeodan T, Zeiler W, Boxem G, Zhao Y. Demand side flexibility: Potentials and building performance implications. Sustain Cities Soc 2016;22:146-63. doi:10.1016/j.scs.2016.02.011.

[6] Knudsen MD, Petersen S. Predictive Control for Demand Response of Domestic Hot Water Preparation in Ultra-Low Temperature District Heating Systems. Energy Build 2017;146:55-64. doi:10.1016/j.enbuild.2017.04.023.

[7] Bertoldi P, Zancanella P, Boza-Kiss B. Demand Response status in EU Member States. 2016. doi:10.2790/962868.

[8] Hu Z, Kim JH, Wang J, Byrne J. Review of dynamic pricing programs in the U.S. And Europe: Status quo and policy recommendations. Renew Sustain Energy Rev 2015;42:743-51. doi:10.1016/j.rser.2014.10.078.

[9] Romani J, Perez G, de Gracia A. Experimental evaluation of a heating radiant wall coupled to a ground source heat pump. Renew Energy 2017;105:520-9. doi:/10.1016/j.renene.2016.12.087.

[10] Shen L, Li Z, Sun Y. Performance evaluation of conventional demand response at building-group-level under different electricity pricings. Energy Build 2016;128:143-54. doi:10.1016/j.enbuild.2016.06.082.

[11] Fischer D, Madani H. On heat pumps in smart grids: A review. Renew Sustain Energy Rev 2017;70:34257. doi:10.1016/j.rser.2016.11.182.

[12] Baeten B, Rogiers F, Helsen L. Reduction of heat pump induced peak electricity use and required generation capacity through thermal energy storage and demand response. Appl Energy 2017;195:184-95. doi:10.1016/j.apenergy.2017.03.055.

[13] Avci M, Erkoc M, Rahmani A, Asfour S. Model predictive HVAC load control in buildings using real-time electricity pricing. Energy Build 2013;60:199-209. doi:10.1016/j.enbuild.2013.01.008.

[14] Alibabaei N, Fung AS, Raahemifar K, Moghimi A. Effects of intelligent strategy planning models on residential HVAC system energy demand and cost during the heating and cooling seasons. Appl Energy 2017;185:29-43. doi:10.1016/j.apenergy.2016.10.062.

[15] Yoon JH, Bladick R, Novoselac A. Demand response for residential buildings based on dynamic price of electricity. Energy Build 2014;80:531-41. doi:10.1016/j.enbuild.2014.05.002.

[16] Klaassen EAM, Asare-Bediako B, De Koning CP, Frunt J, Slootweg JG. Assessment of an algorithm to utilize heat pump flexibility-theory and practice. 2015 IEEE Eindhoven PowerTech, PowerTech 2015 2015:0-5. doi:10.1109/PTC.2015.7232783.

[17] Carvalho AD, Moura P, Vaz GC, De Almeida AT. Ground source heat pumps as high efficient solutions for building space conditioning and for integration in smart grids. Energy Convers Manag 2015;103:991-1007. doi:10.1016/j.enconman.2015.07.032.

[18] Fraga C, Hollmuller P, Mermoud F, Lachal B. Solar assisted heat pump system for multifamily buildings: Towards a seasonal performance factor of 5 ? Numerical sensitivity analysis based on a monitored case study. Sol Energy 2017;146:543-64. doi:10.1016/j.solener.2017.02.008.

[19] Perez KX, Baldea M, Edgar TF. Integrated HVAC management and optimal scheduling of smart appliances for community peak load reduction. Energy Build 2016;123:34-40. doi:10.1016/j.enbuild.2016.04.003.

[20] Escrivá-Escrivá G, Segura-Heras I, Alcázar-Ortega M. Application of an energy management and control system to assess the potential of different control strategies in HVAC systems. Energy Build 
2010;42:2258-67. doi:10.1016/j.enbuild.2010.07.023.

[21] Korkas CD, Baldi S, Michailidis I, Kosmatopoulos EB. Occupancy-based demand response and thermal comfort optimization in microgrids with renewable energy sources and energy storage. Appl Energy 2016;163:93-104. doi:10.1016/j.apenergy.2015.10.140.

[22] Ghahramani A, Zhang K, Dutta K, Yang Z, Becerik-Gerber B. Energy savings from temperature setpoints and deadband: Quantifying the influence of building and system properties on savings. Appl Energy 2016;165:930-42. doi:10.1016/j.apenergy.2015.12.115.

[23] Alimohammadisagvand B, Alam S, Mubbashir Ali, Merkebu Degefa JJ, Siren K. Influence of energy demand response actions on thermal comfort and energy cost in electrically heated residential houses. Indoor Built Environ 2015;0:1-19. doi:10.1177/1420326X15608514.

[24] Heinen S, Turner W, Cradden L, McDermott F, O'Malley M. Electrification of residential space heating considering coincidental weather events and building thermal inertia: A system-wide planning analysis. Energy 2017;127:136-54. doi:10.1016/j.energy.2017.03.102.

[25] Yau YH, Lee SK. Feasibility study of an ice slurry-cooling coil for HVAC and R systems in a tropical building. Appl Energy 2010;87:2699-711. doi:10.1016/j.apenergy.2010.02.025.

[26] Patteeuw D, Henze GP, Helsen L. Comparison of load shifting incentives for low-energy buildings with heat pumps to attain grid flexibility benefits. Appl Energy 2016;167:80-92. doi:10.1016/j.apenergy.2016.01.036.

[27] Yoon JH, Baldick R, Novoselac A. Demand response control of residential HVAC loads based on dynamic electricity prices and economic analysis. Sci Technol Built Environ 2016;4731:1-15. doi:10.1080/23744731.2016.1195659.

[28] Klein SA. TRNSYS 17: A Transient System Simulation Program. Sol Energy Lab Univ Wisconsin, Madison, USA 2010;1:1-5. 